\author{
ACCELERATOR DEPARTMENT \\ BROOKHAVEN NATIONAL LABORATORY \\ ASSOCIATED UNIVERSITIES, INC. \\ UPTON, NEW YORK 11973
}

\title{
GUIDE FOR THE ORGANIZATION OF THE \\ CONFERENCE ON THE INTERSECTIONS BETWEEN \\ PARTICLE AND NUCLEAR PHYSICS
}

\author{
CHERYL CONRAD \\ BROOKHAVEN NATIONAL LABORATORY \\ ASSOCIATED UNIVERSITIES, INC. \\ UPTON, NEW YORK 11973
}

JUNE 29,1984 
Foreword . . . . . . . . . . . . . . . . . . . . . . iv.

Duties of Conference Chairmen. . . . . . . . . . . . . . . 1

Duties of Conference Secretary (General and in Preparation

for Conference) . . . . . . . . . . . . . . . . . 2

Hotel Questicanaire. . . . . . . . . . . . . . . . 6

Contents of Mailings . . . . . . . . . . . . . . . . . . 9

Procedure for Processing Registration Forms. . . . . . . . . . . 10

Supplies for Conference. . . . . . . . . . . . . . . . . 11

Checklist for Hotel. . . . . . . . . . . . . . . . . 13

Checklist for Parallel Session Coordinators. . . . . . . . . . . . 14

Checklist for Plenary Session Chairmen . . . . . . . . . . . . . 15

Checklist for Secretaries at Conference. . . . . . . . . . . . . 16

Registration Procedure at Conference . . . . . . . . . . . . . . 18

Sample Formats, Forms, Letters, and Handouts

Abstract. . . . . . . . . . . . . . . . . . . . 20

AIP Copyright Form. . . . . . . . . . . . . . . . . 21

AIP Format Instructions . . . . . . . . . . . . . . . 23

Announcement of Conference Sent to Physics Magazines. . . . . . 27

Financial Reports--Summary of Deposits/Receipts

and Deposits/Expenses............... 28

Flyer . . . . . . . . . . . . . . . . . . . . 30

Letter Acknowledging Receipt of Letter of Recomnendetion. . . . . 31

Letter Informing Participant of Scholarship Award . . . . . . . . 32

Letter of Invitation for Spouses to Complimentary Continental

Breakfast at Conference. . . . . . . . . . . . . 33

Letter of Invitation to Attend Conference . . . . . . . . . . 34

Letter Requesting Parallel Session Coordinators to Send to

Conference Secretary Copies of Their Correspondence. . . . . 36

Letter to Participants to be Included in Participants' Packets. • . 37

Letter to Participants to be Included in Second Mailing . . . . . . 39

Letter to People Wanting Scholarships to Send Letter of

Recommendation .......................... 41

Letter to Plenary Session Chairmen. . . . . . . . . . . . . 42

Letter to Plenary Speakers. . . . . . . . . . . . . . 43

Letterhead. . . . . . . . . . . . . . . . . . 44

List of Contributed Papers. . . . . . . . . . . . . . . 45

List of Parallel Session Coordinators . . . . . . . . . . . . 46

List of Plenary Talks and Plenary Session Chairnen. . . . . . . 48

Master Conference Schedule. . . . . . . . . . . . . . 52

Meeting Room Floor Plan . . . . . . . . . . . . . . 53 
Parallel Session Schedules (each session separately and master schedule). . . . . . . . . . 54

Poster. . . . . . . . . . . . . ........ 56

Receipt . . . . . . . . . . . . . . . . . . 57

Registration Form . . . . . . . . . . . . . . . . 58

Social Activities Questionnaire . . . . . . . . . . . . . 59

Social Activity Tickets . . . . . . . . . . . . . . . 60

Sticker . . . . . . . . . . . . . . . . . . . . 61

Transportation Sheet.. . . . . . . . . . . . . . . 62

Travel Assistance Request Form. . . . . . . . . . . . 63

Appendix 1: Conference Participants . . . . . . . . . . . 65

Appendix 2: Conference Secretaries. . . . . . . . . . . . 72 


\section{Foreword}

This guide is prepared to help in the job of organizing future conferences. It contains advice based on the experience obtained by Joanne Day, June Goshi, Lorraine Gray, Marion Heimerle, Roberta Marinuzzi, Karen Poelakker, Sue Streicher, and myself in conducting the very successful Conference on the Intersections between Particle and Nuclear Physics at Steamboat Springs, Colorado on May 23-30, 1984 .

I would like to especially thank Marion Heimerle, the Conference Secretary, and Alan Krisch, one of the Conference Chairmen, for giving me the opportunity to serve during the past year as a conference secretary and thus to obtain a great deal of valuable experience and interesting knowledge.

Chery1 Conrad

Brookhaven National Laboratory June 1984 


\section{Duties of Conference Chairmen}

Arrange for funding and sponsorship.

Select location:

Propose appropriate dates for conference.

Visit the hotel and thoroughly investigate the conference facilities and accommodations. (Perhaps prior to your visit to the hotel, you should send them the Hotel Questionnaire on pages 6-8 of this guide.)

Prepare budget and decide on registration fee.

Arrange for posters and announcements in physics magazines.

Arrange for parallel session coordinators.

Choose a publisher for the proceedings.

Designate an editor.

Designate a Conference Secretary and select and notify the secretaries who will be going to the conference.

Arrange for a secretary to go out to the hotel to check its facilities.

Set up the conference schedule.

Keep in contact with the parallel session coordinators to see how they are progressing in setting up their sessions.

Invite the plenary speakers and chairmen.

Decide on financial assistance and evaluate scholarship waiver requests.

Inform the plenary session chairmen of the day and time of their chairing.

Arrange for a photographer. 
Genera1

Be sure the conference location and facilities have been thoroughly investigated (accommodations, meeting rooms, restaurants, activities). See Hotel Questionnaire on pages $6-8$ of this guide.

Order mailing labels for initial mailing--APS Division of Particles \& Fields and APS Division of Nuclear Physics from AIP, 335 East 45th Street, New York, NY 10017, 212-661-9404--order two sets of each, one pressure sensitive to be put on mailing envelopes by hand, and a second set, cheshire, to be used for reference). Ask the AIP to sort the lists to eliminate duplications. (The cost in 1984 was $\$ 683.81$. )

Have logo, posters, stationery, and conference stickers made (these stickers are used as return address labels). A copy of the logo and poster is on file at the Brookhaven National Laboratory Graphic Arts Department. Contact Bobbie Samaritter at 516-282-7288.

Order envelopes ( $\$ 11$ and $\#_{10}$ ).

Order AIP copyright forms and format instructions from Hugh Wolfe, AIP, 335 East 45th Street, New York, NY 10017, 212-661-9404--if AIP is going to publish the proceedings. The compilation of the proceedings was handled by a parallel session coordinator and his secretary.

Have return address printed on 111 mailing envelopes and $\|_{10}$ return envelopes (in addition to printing the mailing address back to the conference secretary).

Prepare mailings (send a sufficient quantity of initial mailing material to parallel session coordinators to forward to invited parallel session speakers) and send stationery to the parallel session coordinators and secretaries.

Send out announcements to various publications (Harold Davis, Editor, Physics Today, 335 East 45th Street, New York, NY 10017; T. Ferbel, Editor, DPF Newsletter, Department of Physics, University of Rochester, Rochester, NY 14627; William Havens, Editor, The Bulletin of the APS, 335 East 45th Street, New York, NY 10017; Brian Southworth, Editor, CERN Courier, European Laboratory for Particle Physics, CERN, 1211 Geneva 23, Switzerland).

Maintain file of registration forms.

As registration forms come in, update list of participants (which includes name, address, phone number, and payment record), lists of contributed papers, suggestions, and participants coming with spouses.

Maintain lists of plenary speakers and plenary session chairmen (both with and without financial information).

Maintain checking accounts and maintain up-to-date lists of (1) receipts and disbursements and (2) receipts and deposits. Make xerox copies of any check drawn on the conference accounts. Make sure a checking account is open in advance in the town of the conference. 
Type scholarship letters and maintain a list of people receiving scholarships. Attach to registration form copies of these letters as well as anything received from the person requesting the scholarship. Give all scholarship requests to conference chairman.

Maintain a list of people receiving scholarship waivers.

Send to the conference chairmen copies of any letters sent to invited plenary speakers or plenary session chairmen (as well as maintaining your own file of copies of these letters).

Request from session coordinators: (1) copies of letters they send out to parallel session speakers and (2) names and amounts for anyone they have given registration waivers or financial assistance.

Have three-part numbered receipts printed (one copy for participant, one copy stapled to the back of the registration form, and one copy for reference).

Send copies of registration forms to the person preparing name badges (have three different colors for badges-one color for session coordinators, a second color for organizing committee members, and a third color for other participants). 
Secretaries should plan on arriving at the conference in sufficient time so that they can work on the day before the conference begins.

Coordinate with other secretaries ordering of xerox equipment, thermofax equipment, typewriters, word processor (if easily accessible), making of name badges, shipping of supplies to conference location.

Have each secretary bring a lab/home institution phone book.

Make arrangements ${ }^{\circ}$ for two telephone lines to be installed (the day before the conference begins) for use during the conference.

Order local maps (street maps) of conference town and ship directly to conference location.

Order briefcases with conference logo and have them shipped directly to conference location (Sue Streicher ordered them from Chip Staley, President, Advertisers Publishing Company, 944 Wal1 Street, P.0. Box 7010, Ann Arbor, MI 48107$7010,313-665-6171$ ).

Ask conference chairmen if someone has been asked to serve as conference photographer.

Request that the hotel prepare, in sufficient quantity to be included in the participants' packets, lists of the various activities and tours available both in the hotel and environs.

Print social activity tickets in sufficient time for them to be numbered at time of printing and then collate them.

Type briefcase name tags which will be put in small envelopes.

Prepare small envelopes (use $\# 10$ envelopes) which will be used to hold the name badges, social activity tickets, and briefcase name tag. Write the participant's name in the upper right hand corner of the envelope. Stuff these small envelopes ahead of time with the briefcase name tag and the social activity tickets. Record the activity ticket number on the registration form (to the right of the conference title on the top of the registration form) and ship these by UPS blue to the conference location.

Prepare, print, and then ship by UPS blue the items that will go in participants' packets:

Introductory letter

Master schedule for entire conference

Lists of plenary talks and topics and parallel session chairmen (without financial information)

Schedules for parallel sessions (both master and individual)

Meeting room floor plan (use a different color, i.e., yellow)

List of participants (name and institution only)

Travel assistance request form (use a different color, i.e., blue)

Activities list from hotel

Print and ship by UPS the Social Activities Questionnaire (this questionnaire is filled out by the conference secretary as each participant registers).

Prepare registration forms for all members of the organizing committee, session coordinators, and invited parallel session speakers (if not sent in). 
On top of the registration forms indicate if the person is a session coordinator (and which topic), if the person is a session chairmen (and the day and time of session being chaired), if the person is a parallel session speaker (the day and time of speaking).

Prepare on post-it pads and put on registration forms any questions or information to be given to participants at time of registration, i.e., do you have any $35 \mathrm{~mm}$ slides (for plenary speakers), do you have any last minute changes in your parallel session schedule (for session coordinators), see _to discuss travel arrangements (for people receiving financial-assistance), the day and time of session being chaired (for plenary session chairmen).

Act as a liasion between people wanting rides from airport to conference.

Have signs made up for the registration desk (REGISTRATION, A-G, $H-O, P-Z$ ), the travel desk, the manuscript desk, the various parallel sessions (xerox enough of these so that a new one can be put up for each session), activities sign-up.

Have sign-up sheets made for the various tourist activities.

Type up invitation for complimentary continental breakfast for spouses or guests (or spouses' program or function).

Type up invitation for organizing committee members for dinner meeting at the end of the conference to discuss the conference.

Send a list of anyone who will be getting financial assistance to the person who is preparing these checks (University of Michigan).

Ask hotel to order flowers for conference desk (i.e., dried flower arrangement) and for any social activity.

Ask hotel to order any special souvenir for participants (i.e., scarves at. Steamboat for barbecue).

Prepare labels for folders for speakers' transparencies. Get the names from the list of plenary talks and parallel session schedules.

Prepare List of Participants Addendum which will be updated and xeroxed at conference location.

Get phone number of weather service and recording.

A few days before leaving for Conference

Call printer (in town of Conference) a few days before arriving to see if he can do any last minute printing (get phone number from hotel).

Bring cash for cashbox.

Buy stamps for postcards and first-class mail.

Take stamp for back of checks, checkbooks, and extra checks.

Take all records. 
Hote1 Questionnaire

(This form should be sent to the hotel in advance of your visit.)

Regarding Accommodations:

Do you have accommodations for about 300 people?.

What is the cost for one person? two people? children?

Will you block rooms for us?

How much is the room deposit? Reservation deadline? What credit card will you accept for the deposit? for payment of the hotel bill?

Do you send out reservation confirmations to the individuals?

What is your room cancellation policy (with deposit refund and without deposit refund)?

Will you print the reservation card with the name and dates of the conference (cost)? Will you provide return envelopes (cost)?

Are there any upgraded rooms available depending on the number of rooms reserved (i.e., a suite at same price for every 50 rooms reserved)?

Do you have special facilities for handicapped people?

Do you have rooms with kitchen facilities?

What hotel facilities are available to the guests (hours, cost)?

Is there free parking (indoor or outdoor)?

Are there any facilities for parking a trailer?

What restaurants within the hotel will be open during the time of the conference?

What is their seating capacity and will they be open early enough for breakfast before the sessions begin?

What other restaurants in the area will be open at the time of the conference? Can you provide us with a list of them (with hours, prices, sample menus)?

What special treatment do you have for VIP's?

What is check-out time and can special arrangements be made for later check-out time for VIP's?

Do you accept or convert foreign currency?

Will the hotel be closed any time between now and the conference?

Regarding Meeting Room Facilities and Conference Office:

What are the sizes and location of your meeting rooms? Do you have a large room to seat 300 people classroom-style and then 5 smaller rooms to seat about 75 people classroom style?

Will there be any conflicting meetings in the hotel?

Can you meet our audiovisual needs--overhead projectors, 35-mm slide projectors, screens, electric pointers, extension cords, and clip-on microphones in each room? Do you have extra equipment and bulbs in case of malfunctioning equipment?

Do you have bulletin boards and blackboards?

What is the cost of using the meetings rooms and renting audiovisual equipment? Do you have equipment/staff to tape-record the discussions?

Will the secretaries' office be near the registration desk? The registration desk and office should be able to be locked and should be available beginning a day before the conference and for the entire length of the conference. Can additional telephones be installed (cost)? They should be installed the day before the conference begins.

Can you provide xeroxing facilities (cost, as a backup)?

Can we have the use of two small rooms for dinner meetings towards the end of the conference (organizing committee meeting and secretaries meeting) (cost)?

How much time is needed for going from the plenary session arrangement to parallel session arrangement and from the parallel session arrangement to the banquet

arrangement?

Will you put up "No Smoking" signs and take out ashtrays?

Will both the heating and air conditioning systems be in working condition at the time of the conference and are they easily adjustable? 
Regarding the master account billing:

Who has authority to approve charges?

Is there tax-exempt status? Do you add the tax to each bill and then subtract it in a lump-sum at the end?

Is an up-front deposit necessary against the master account bill?

What can be charged to the master account bill?

What is the gratuity rate?

Are there any set up costs?

When is payment expected for the master account bill?

\section{Regarding Amenities:}

What is the charge for coffee and danish for the breaks (cookies with afternoon break), wine and cheese reception, banquet, spouses' continental breakfast?

Do you have sample menus for the wine and cheese reception and banquet?

Can we order special wine?

Do you serve special meals upon request, i.e., Kosher or vegetarian meals?

Will someone be available to collect the social activity tickets at the appropriate function?

Is there a travel agent available if needed to help with travel arrangements?

Do you have a babysitting service or list of recommended babysitters?

\section{Regarding Transportation:}

Do you provide transportation for guests to and from airport (cost)?

What public transportation is available? Can you provide us with bus schedules (days of week and hours) and taxi services (phone numbers)?

Is there a special deal on rental cars?

Genera1

Are there any houses of worship in the area (1ocation, denomination, hours open)?

What is your check-cashing policy?

Do you have safe deposit boxes?

Can you provide us with enough hotel brochures to send out with our initial mailing (about 7000) (cost)?

Can you provide us with meeting room floor plans (about 350) for distribution at the time of the conference (cost)?

Can you prepare a letter telling about the hotel facilities and activities that can be sent to participants (with the second mailing--about six weeks before the conference)? Will you send us enough copies (about 350) or will we have to print them (cost)?

Can you provide lists of activities and obtain tour information with the names of contacts for the various activities? Can you also obtain a sufficient quantity of any specialized map (i.e., hiking maps) that are either free or will cost extra?

Can you provide local maps (about 350, cost)?

Who are the hotel contacts concerning reservations, conference facilities, banquet, social activities? 
Can you arrange for a band (if appropriate for a social activity, cost)?

Can we order any special souvenir, if appropriate, for a social activity (cost)?

What are your deadlines concerning guarantee for number of attendees at social activities, ordering special wine, etc.? 
Initial Mailing to Potential Participants*:

Letter of invitation $\dagger$

Flyer (smaller version of poster) $\dagger$

Brochure from hotel

Registration form $\dagger$

Abstract form $* * \dagger$

List of parallel session coordinators with addresses and phone numbers** $\dagger$

Hotel reservation card

Return envelope

Second Mailing to All Who Registered + Session Coordinators + Organizing

Committee + Carbon Copy People + Conference Secretaries:

Letter $\dagger$

Tentative master schedule $\dagger$

List of invited speakers and topics for plenary sessions and list of plenary session chairmen (without financial information) $\dagger$

Master schedule of parallel sessions $\dagger$

List of parallel session coordinators with addresses and phone numbers $\dagger$

AIP copyright form $\dagger$

AIP format instructions $\dagger$

Letter from hotel listing facilities and activities

Transportation sheet listing local airline schedule, bus schedule, motels/hotels near airport, taxi phone numbers $\dagger$

Extra hotel reservation card

Intermediate Mailings to Session Coordinators and Organizing Committee

Once registration forms have begun to arrive, compile lists of contributed papers and suggestions and mail these lists along with updates of list of participants about every 10 days.

*Obtain mailing labels for APS Division of Particles \& Fields and APS Division of Nuclear Physics from AIP, 335 East 45th Street, New York, NY 10017, 212-661-9404. Order two sets--one set of pressure sensitive labels to be used as mailing labels and the second set called cheshire which is used for reference. Ask AIP to sort the DPF and DNP 1ists to eliminate duplications.

**These were not included in the initial mailing, but I suggest that they be included.

†Samples included in this guide. 
Procedure for Processing Registration Forms

1. When registration forms are received, date stamp registration form in the upper left corner.

2. If no hotel card accompanies registration form, write "no.hotel card" in the middle of the right margin of the registration form.

If a check accompanies the hotel registration card, write "check enclosed" on the right side of the hotel registration card and clip the check to the back of the card. (On Tuesdays, mail the checks, hotel registration cards, and a letter to the reservations manager of the hotel by Express Mail.)

3. Xerox hotel registration card and put an $X$ in the upper left corner of the hotel registration card to indicate that the card was xeroxed.

4. Xerox registration forms and put an $X$ in the upper left corner of the registration form to indicate the card was xeroxed. Put these xerox copies in an envelope to be sent to Roberta Marinuzzi of Los Alamos who will be making the name badges. (These are sent to Roberta once a week by express mai1.)

5. Fill out a receipt for any checks received (both for registration fee and hotel deposit) and mail the white copy to the participant. Staple the yellow copy to the back of the registration form and keep the pink copies together.

6. Stamp the back of the registration fee checks with the "Deposit to the account of ..." stamp and write the account number underneath. On Fridays, these checks will be deposited in the bank on site. (Prior to making a deposit, xerox each check.)

7. Add each participant to the participants list. Write " $L$ " in red to the left of the name on the registration form to indicate that the name was entered in the word processor.

8. Add participant to spouse list and no hotel card list, if applicable.

9. Add to the contributed paper 1ist, the invited paper 1ist, or the suggested speaker, etc. list any entry on registration forms regardless of whether the person is attending. Write " $\mathrm{L}$ " in red to the left of the entry on the registration form to indicate that it was entered in the word processor.

10. File the registration form in the appropriate file.

Note: For the 1984 conference, the hotel registration cards were sent to the conference secretary. If the participants are now supposed to send the hotel registration cards directly to the hotel, disregard all items relating to them. 
1 word processor + disks, ribbons (if easily available)

2 thermofax machines + transparencies ( 12 boxes), pens (50), eraser for pens

3 xerox machines-one with automatic feed feature + paper, toner

3 typewriters + ribbons, elements (prestige elite, orator, symbol), lift-off tape (2 rolls)

sno pak (10 bottles), liquid paper for ink and xerox copies ( 4 bottles each) blue editing pencils (6)

Avery correction tape (1 line) (2 packages)

conference stationery

retractable pens

no. 2-1/2 pencils (200)

assorted colored pencils ( 5 boxes)

pencil sharpener (battery operated)

sharpie pens (500) (enough so that one can be put in each participant's packet)

double ended pens (blue \& red) ( 7 dozen)

bond paper (25 reams $8-1 / 2 \times 11$ and 5 reams $8-1 / 2 \times 14$ ) (we had much too much of this)

lined tablets (500-8-1/2 x 11) (enough so that one can be put in each participant's packet)

unlined pads ( 1 dozen $5 \times 8$ and 2 dozen little ones)

telephone message pads (11)

post-it pads ( 2 dozen $2 " \times 4 "$ and $103 " \times 3 "$ )

rulers (2 12" and 2 18")

scotch tape (10 rolls) and dispensers (4)

assorted rubber bands ( 2 boxes)

staplers ( 5 ) and staples (10 boxes)

heavy duty stapler (did not have one but we could have used one)

staple removers (4)

rubber cement ( 4 bottles)

glue sticks (2)

scissors (3)

\section{dictionary (1)}

push pins for bulletin board ( 2 boxes, but we could have used more)

binder clips (smal1--10 boxes, 12 per box and medium--10 boxes, 12 per box)

medium paper clips ( 10 boxes, 50 per box)

large paper clips ( 10 boxes, 12 per box)

paper fasteners ( 2 boxes)

plastic cups for clips (4)

file folders (500--enough so that they can be used for speakers' transparencies)

file folder labels ( 2 boxes)

receipt pads (not necessarily printed with logo) to give for xerox money (we did not have these but it would be useful in order to keep track of the money) 
3 ring binders (6)

see through report covers and backbones (100)

3 hole punches (2) and 2 hole punches (2)

wall calendars (2)

wall clock (didn't have, but it would have been nice)

letter openers (2)

hole reinforcements ( 2 boxes)

avery mailing labels ( 20 boxes, 4" $\times 2$ ")

chalk (1 box each of yellow and white) and erasers (2)

2 staḿp pads

lab phone books

airline guides

DOE phone book

extra:

letterhead

social activity tickets

conference stickers

\#10 return envelopes

\#11 envelopes

registration forms

meeting room floor plans

travel assistance request forms

master conference schedule

paralle1 session schedules

lists of plenary talks and topics and session chairmen

copyright forms

AIP instructions

large posters

flyers

Colorado brochures

vest maps

three part receipts

$9 \times 11$ brown envelopes (with return address)

intra-lab envelopes

steno pads (11)

first aid kit (didn't have one but it would have been useful)

bell (to signal start of sessions--hotel may provide)

timers (6)

electric pointers (hotel may provide)

cash box (2)

stamps (first class and postcard)

calculator with tape 


\section{Checklist for Hotel}

Do you have enough video equipment--overhead projectors, pointers, $35 \mathrm{~mm}-\mathrm{s} 1$ ide projectors, screens, extra projector bulbs, clip-on microphones, extension cords?

Wi11 there be ice water and glasses in each room at the start of all sessions?

Have you put up "No Smoking" signs and removed ashtrays in the rooms used by the participants?

Have you provided enough bulletin boards, desks, and chairs for secretaries?

Have you provided enough garbage containers at the registration desk and any other stations used by the secretaries? 
Before Conference

Have you sent the initial mailing contents to the people you invite to speak?

Have you requested that the speakers bring four xeroxed sets of their transparencies to the conference (one for each session coordinator, one for the manuscript secretary, and one for the summary speaker) in addition to their typed conference paper and signed copyright form? (The compilation of the proceedings was handled by one of the parallel session coordinators and his secretary.)

Have you sent to the conference secretary copies of letters you sent to invited parallel session speakers?

Have you submitted your schedule to the conference secretary approximately three weeks before the conference?

Have you notified the parallel session speakers of the day and time of their talk?

Have you notified the conference secretary of anyone getting a registration waiver or financial assistance (and the amount)?

At the Conference

Upon registering, please notify the secretary of any last minute changes in the schedule or anyone getting a registration waiver or financial assistance. 
Checklist for Plenary Session Chairmen

Do you know which session you are chairing?

Ask questioners to please stand when asking questions.

Repeat questions from audience before speaker starts to answer. 


\section{Day Before Conference}

Check that phones are installed.

Take inventory of the supplies and purchase anything needed; purchase mints and paper dishes.

Take to printer any last minute items needed (cal1 printer ahead of time to see if he is able to do printing).

Check with hotel that they have all video equipment and microphones.

Put name badges in small envelopes and make small envelopes and badges for any late participants.

Assemble participants' packets.

Give secretaries their jobs:

3 people at registration area for the first two or three days and then only two people are needed

1 person at travel

1 person at manuscript desk

2 for xeroxing--these people will also run slide projector and attend to the lights even if the person says they do not need help with their slides

1 troubleshooter

Have secretaries get instructions on how to run the video equipment.

Give financial assistance checks to whomever is distributing them.

Get local telephone directory and emergency telephone numbers.

Set up registration area and office.

Notify hotel of any VIP's who should be allowed to check out of their room later than the posted check-out time.

\section{Each Day of the Conference}

Have bell to signal the start of the sessions.

Before each session, check that each room has operational projectors, a microphone, pointer, timer, extra transparencies and pens, and ice water and glasses.

At the end of each day, take out of rooms the pointers and timers and lock them up in the registration area.

Before parallel sessions, put up signs •

Deposit money in the bank. (Xerox each check and travelers check. Run a tape of the checks and travelers checks and attach it to the deposit slip. Make a Xerox of the tape also.) 
At End of the Conference

Prepare List of Participants Addendum.

Have a dinner meeting to discuss the running of the conference.

Arrange for the pick up of office equipment and clean the office/registration area. 
1. Ask person what he is her name is.

2. Find the registration form and put an $R$ to the right of the words "Registration Form."

3. If marked paid, go to \#4.

If marked SCHOL or WAIVED, do not ask for money and go to \#4.

If not paid, collect $\$ 125$, put the money in cashbox, and write a receipt. Give the person the white copy, staple the yellow copy to the back of the registration form, and put the pink copies in a pile. Write "Paid" to the left of the words "Will pay $\$ 125$ at registration."

4. If there is a question on a post-it sheet of paper, ask it.

5. Ask participants the questions on the "Social Activities Questionnaire" and ask if they want to purchase any extra tickets. If they do, write them a receipt and record the number of the tickets at the bottom of the questionnaire.

6. If the person was accompanied by a spouse or friend, give them an invitation to the complimentary continental breakfast.

7. Give the participant a briefcase and the smaller envelope which contains the name badge, social activity tickets, and name tag for envelope.

8. Give members of the organizing committee an invitation to the dinner meeting taking place at the end of the conference. 
Sample Formats, Forms, Letters, and Handouts 
CONFERENCE ON THE INTERSECTIONS BETWEEN PARTICLE AND NUCLEAR PHYSICS

The Sheraton at Steamboat Springs, Colorado

May 24-31, 1986

ABSTRACT

DEADLINE: APRIL 1,1986

NAME AND ADDRESS of Author for Correspondence:

TELEPHONE :

TELEX:

SESSION/TOPIC IDENTIFICATION

Accelerator

Electron and Muon

Hadron

Heavy Ion

Hypernuclear

Kaon

Neutrino

Non-Accelerator

Spin
PROJECTION EQUIPMENT NEEDED:

$35 \mathrm{~mm}$ slide projector

Overhead projector

Other (indicate)

BRING FOUR XEROX COPIES OF YOUR VIEWGRAPHS OR 35 MM SLIDES TO THE CONFERENCE AS WELL AS THE TYPED CONFERENCE PAPER (ACCORDING TO AIP FORMAT DIRECTIONS) AND THE SIGNED COPYRIGHTT FORM.

MAIL THIS FORM BY APRIL 1, 1986 TO: 
Copyright to the article entitled

by

\title{
All Authors
}

is hercby transferred to the AIP (to the extent transferable* under applicable national laws), effective if and when the article is accepted for publication in AIP Conference Proceedings.

However, the authors reserve the following rights:

(1) All proprietary rights other than copyright, such as patent rights.

(2) The right to grant or refuse permission to third parties to republish all or part of the article or translations thereof. In the case of whole articles, such third parties must obtain AIP's written permission as well. However, such permission will not be refused by AIP except at the direction of the author. AIP may grant rights with respect to entire volumes.

(3) The right to use all or part of this article in future works of their own, such as lectures, lecture notes, press releases, reviews, text books, or reprint books.

(4) In the case of a "work made for hire," the right of the employer to make copies of this article for his own use, but not for resale.

To be signed by at least one of the authors (who agrees to inform the others, if any) or, in the case of a "work made for hire," by the employer. \\ The signed statement must be received by the conference management before the \\ manuscript can be accepted for publication.
}

*An author who is a U.S. Government officer or employee and prepared the submitted article as part of his or her official duties does not own any copyright in it. If at least one of the authors is not in this category, that author should sign above. If all the authors are in this category check the box here and return this form unsigned.

* Order these directly from AIP, 335 East 45th Street, New York, NY 10017, 


\section{CONTRIBUTE YOUR COPYRIGHT}

(Reprint of an editorial by J.A. Krumhansl, Chairman, AIP Publishing Policy Committee, in the September 1977 issue of Physics Today)

In 1978 a new copyright law becomes effective, and one of the results is that AIP and most member-society journals will be asking authors for transfer of copyright on each article. All of us should understand how this has come about and why it is important.

Traditionally a transfer of copyright from physicist authors to the society owning the journal was assumed to be implicit in the process of submitting a manuscript and getting it refereed and accepted for publication. AIP journals merely carried a statement on the inside of the front cover that "submission ... is a representation that the manuscript has not been copyrighted, published, or currently submitted for publication elsewhere." On the same page and elsewhere in each journal issue the copyright notice was printed and was taken to apply to the journal issue as a whole and to all the articles in it separately. Armed with this understanding, AIP could not only fublish the journal, but could distribute reprints of separate articles, authorize others to reprint selectively or cover-to-cover, negotiate translation rights (for example, Review of Scientific Instruments into Russian), authorize indexing and abstracting services to use material from the journals, authorize free fair-use copying by individuals and libraries, produce and market microform editions of the journals and computer tapes of abstracts, etc., etc. All of this has been done successfully in the spirit of actively advancing and diffusing the knowledge of physics.

The new (1978) US copyright law changes the situation in at least three important respects. First, it vests statutory copyright with the authors, or with their employers in the case of a "work made for hire," from the moment a manuscript is written, whether or not this copyright is officially registered. This copyright can now be transferred only in a formal written manner, and the submission of a manuscript for publication gives the publisher only the right to publish it once in the printed journal.

There is a second major change in the law. The copyright to a journal issue, which AIP can register formally with the Registrar of Copyrights and print on the inside of the front cover of the journal, will now apply only to the issue as a whole, but not to the articles separately. In order for an article to be covered separately, a copyright notice will have to appear on its first page, and this particularly requires a transfer of copyright to AlP from the author. Otherwise, for each future republication use the original authors would have to give written permission. This would be utterly cumbersome and would clearly set back the whole current information-distribution system.

The third major change in the law affecting journals is a much more rigorous definition of the conditions under which libraries may make photographic copies. Individuals (or nonprofit libraries acting for them) will continue to be free to make copies of articles for their use in research and teaching. However, for commercial libraries and microfilm services the limits to copying are severe; without clear authorization, for example, from AIP or a member society, distribution through these channels simply cannot legally take place.

This new law provides long-needed protection for authors of popular works, composers and the like. However, our journals will need the copyright to continue the broad dissemination of physics. Thus a transfer-of-copyright agreement will be required with manuscript submission. The author will continue to hold all other traditional rights. For example, proprietary rights other than copyright, such as patent rights, are not transferred. It will continue to be an explicit part of AIP permissions policy that anyone who wishes to republish a figure, table, or other brief excerft from an article will need the author's permission and, if the whole article is to be republished, AIP's permission as well. In either case the author has veto rights over such use. Finally, the author retains the right to use the article in his or her future works, for example, to include it in a reprint volume of which he or she is the editor. Naturally, authors as individuals will also have fair-use privileges for research and teaching (see news story in the September issue of Physics Today p. 85).

In summary, although this new situation complicates our lives somewhat, it is not only essential to the well-being of the journals, but also is a distinct advantage to authors desiring wide distribution of their work, to transfer copyright .... so that we may continue to disseminate physics broadly, and promptly.

AlP permissions policy statement as printed on the inside front cover of AIP journals:

Copyright (c) 1978, American Institute of Physics. Individual readers of this journal, and nonprofit libraries acting for them, are freely permitted to make fair use of the material in it, such as to copy an article for use in teaching or research. Permission is granted to quote from this journal in scientific works with the customary acknowledgment of the source. To reprint a figure, table, or other excerpt requires, in addition, the consent of one of the original authors and notification of AIP. Republication or systematic or multiple reproduction of any material in this journal (including abstracts) is permitted only under license from AIP; in addition, AIP may require that permission also be obtained from one of the authors. Address inquiries and notices to Director, Publications Division, AIP. 
(AIP Format Instructions) *

AUTHOR'S MANUAL FOR CONFERENCE PROCEEDINGS

Prepared by

Hugh C. Wolfe, Serles Editor, AIP Conference Proceedings

American Institute of Physics, 335 E. 45th St., New York, N.Y. 10017

\section{INTRODUCTION}

The American Institute of Physics is publishing the proceedings of. appropriate conferences in physics in the AIP Conference Proceedings series. In hard covers, the book size will be $63 / 4^{\prime \prime} \times 91 / 2^{\prime \prime}$. In lieu of the page charges characteristic of journal publication, the conference management is responsible for refereeing and editing the papers and each author (or the conference management for him) will subsequently be responsible for preparing a typewriter-composed copy of his paper in camera-ready form for direct offset reproduction. Instructions for the preparation of the paper in proper form are given below and in the sample paper, which is in the required format except that it is printed here, for economy, on two sides of the same sheet. The AIP Style Manual, availabie from AIP for $\$ 7.50$, provides guidance for the structure and style of a technical paper, recommended abbreviations, etc.

GENERAL GUIDE LINES

The typing should be on good quality $81 / 2^{\prime \prime} \times 11$ " white bond paper, using one side only. A rectangle $53 / 4^{\prime \prime}$ wide by $83 / 4$ ". high (146 $\times 222 \mathrm{~mm})$ should be drawn on each sheet using a very light blue pencil, such as Eagle Sky Blue 740 1/2, which will not be reproduced in the photographic copying. All text and figures must be kept within this rectangle. Pages will be reduced by $15 \%$ in the printing process. Typing should be done with a new carbon ribbon on an electric typewriter in good condition to give pages of uniform density. Elite type (12 characters per inch) or an equivalent proportionalspaced type is preferred. Unusual type faces (script, italic) are not to be used except possibly for the symbols for physical quantities.

Except where blank lines are required, the material should all be typed single-spaced, which means 6 lines per inch. It may be advantageous to allow an extra half space above a line containing superscripts and below a line containing subscripts.

\section{CORRECTIONS}

Erasures must be avolded. Errors of one or two letters may be corrected with Correctype, Snowpake, or similar means; larger errors should be repaired by typing a new line or paragraph and pasting it neatly in place. In general, a correction which is undetectable in a good Xerox copy will be satisfactory.

* Order these directly from AIP, 335 East 45th Street, New York, NY 10017, 212-661-9404, ext. 631 (Hugh Wolfe, publisher) 
TITLE; AUTHOR, ADDRESS, ABSTRACT

The title should be placed below the top of the blue rectangle, leaving above it space equivalent to one line, centered, in capital letters (except for symbols, such as those for chemical elements, that require lower-case letters). The title may occupy one or more lines, single spaced. Skipping one line, enter the names of the authors, centered, in capitals and lower-case letters with given names or initials preceding the last name. Authors with the same address should be grouped together. Without skipping a line, give the author's corporate address, i.e., the institution where the work was done, including city, state and zip code.

With one blank line above and below it; enter the centered heading ABSTRACT. This should be followed by the abstract, preferably of not over 200 words.

\section{HEADINGS, TEXT}

Each heading (such as INTRODUCTION, CONCLUSION, etc.) should be in all capitals, centered, with one blank line above and below it. The main text should use the full width of the blue rectangle. Each paragraph should start with a 5-space indentation and no lines should be left between paragraphs.

\section{" LENGTH}

The length of the paper must be kept within the limits established by the conference management.

\section{DELIVERY}

The author should send the original of the finished manuscript to the conference management as soon as possible after editing, so that publication of the proceedings may be expedited. He should keep a good Xerox or equivalent copy.

\section{PAGE NUMBERS}

Do not type numbers on the manuscript. To help keep the pages in proper order, write in page numbers, centered at the top of each page, in light blue pencil. 


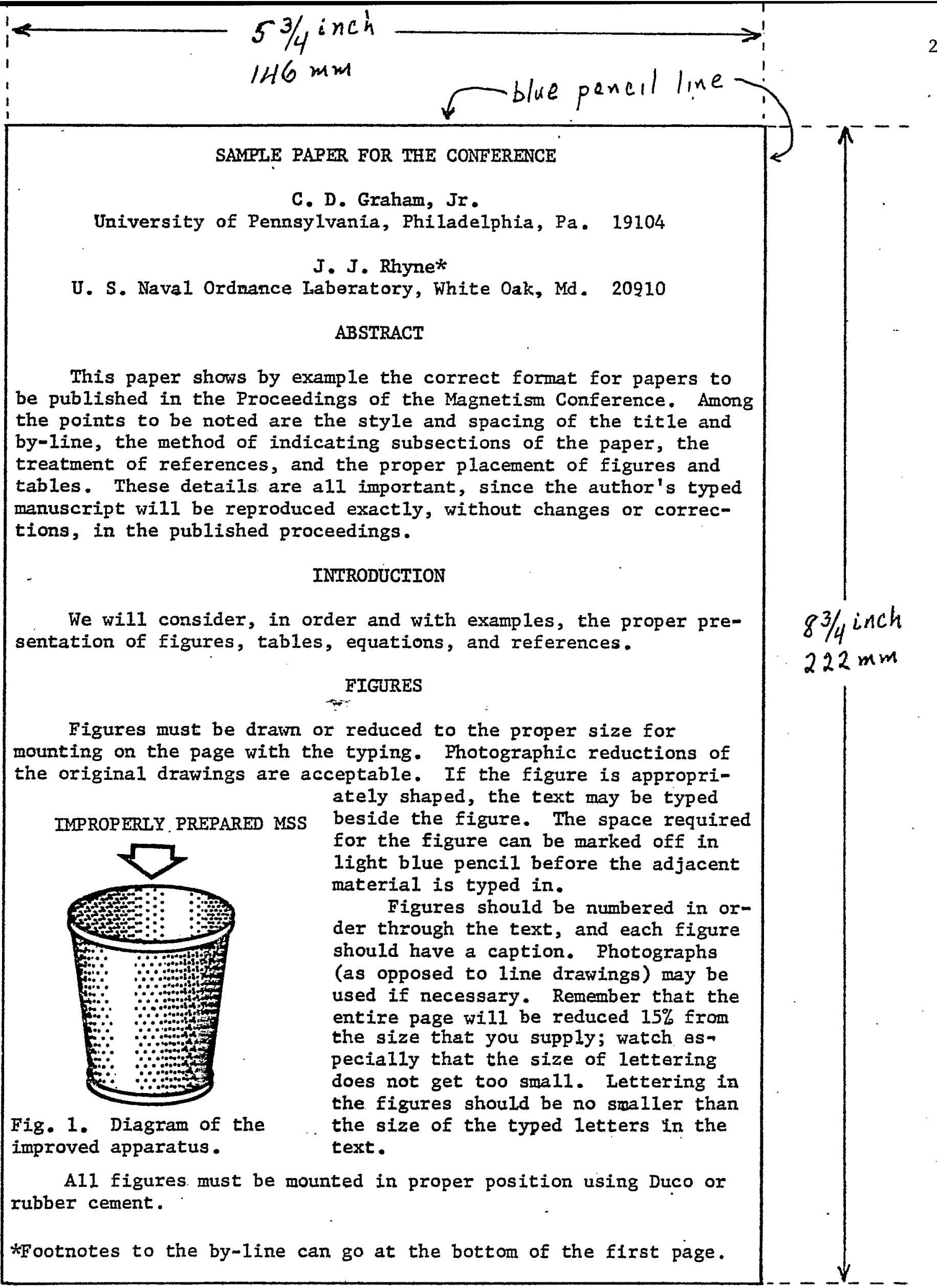




\section{TABLES}

Tables are best typed separately and pasted in 1ike figures. Ruled lines, horizontal and vertical, are better drawn with black ink than produced by typing. Tables are identified with Roman numerals, and each should have a caption.

Table I Values of $x$ and $y$ derlved from the data

\begin{tabular}{|ccccc|}
\hline Run No. & $\begin{array}{c}\text { parameter } \\
\text { (ergs) }\end{array}$ & $\begin{array}{c}\text { parameter } \\
\text { (barns) }\end{array}$ & $\begin{array}{c}\mathrm{x} \\
\text { (scoops/acre) }\end{array}$ & $\begin{array}{c}y \\
\text { (tons) }\end{array}$ \\
\hline 1 & $1.2 \times 10^{3}$ & 0.0023 & 15.4 & 9.8 \\
2 & $0.8 \times 10^{6}$ & 0.0011 & 9.3 & 9.7 \\
\hline & EQUATIONS & & \\
\hline
\end{tabular}

Equations should be centered on the page, with a blank line above and below. They should be numbered consecutively through the paper, using arabic numbers in parentheses at the right hand margin:

$$
z=k_{0}(\sinh (a-b))^{3}+\frac{1}{2} \ln (\tan \theta)
$$

Typed equations are by far the best-looking. Symbols not available on the typewriter, or equations with multiple subscripts and superscripts, may have to be hand-written. Seek someone with a skilled hand, and use black ink. Be careful to distinguish the letter "ell" from the numeral "one" where confusion might result. A symbol for a vector quantity should have an arrow typed or drawn over it.

\section{REF ERENCES}

References are indicated by superscript numbers 1,2 in order through the text, and are collected at the end. References should be given in the standard AIP style: author, jourmal (abbreviated), volume number, page, year.

1. J. W. Bloggs, Phys. Rev. B2, 1333 (1969).

2. E. J. Bliggs, A Treatise on Treatises (McGraw-Hill, N. Y., 1962), p. 454 . 
CONFERENCE ON THE INTERSECTIONS BETWEEN PARTICLE AND NUCLEAR PHYSICS

The Sheraton at Steamboat Springs, Colorado

May $23-30,1984$

Announcing the

CONFERENCE ON THE INTERSECTIONS BETWEEN PARTICLE AND NUCLEAR PHYSICS

This conference, open to all, will be held on May 23-30, 1984 in Steamboat Springs, Colorado, U.S.A. The meetings will focus on the physics interests of the many diverse groups who work in Particle and/or Nuclear Physics. The conference has been designed to promote dialogue between these groups, highlighting the importance of Nuclear and Particle Physics in the 1 to $100 \mathrm{GeV} / \mathrm{c} \mathrm{re-}$ gion. Morning sessions will feature colloquium-type lectures on many important topics in both fields and shorter presentations of interesting new results. The conference will normally reconvene in the late afternoon with parallel workshop meetings on a wide variety of topics: the physics of electrons and muons, hadrons, heavy ions, kaon decay, neutrinos, spin, hypernuclei, accelerator physics, and non-accelerator experiments. In general, each workshop will be jointly run by one Particle and one Nuclear coordinator. The workshops will concentrate on discussions of shared facilities and techniques and common scientific and technical problems will be discussed.

The co-chairmen of the organizing committee are A.D. Krisch (Michigan) and M.H. Macfarlane (Indiana), and the committee members are G.M. Bunce (Brookhaven), J.W. Cronin (Chicago), G.R. Farrar (Rutgers and Inst. Adv. Study), V.W. Hughes (Yale), H.E. Jackson (Argonne), T.D. Lee (Columbia), J.S. McCarthy (Virginia), R.E. Mischke (Los Alamos), E.J. Moniz (M.I.T.), T.A. O'Halloran (IIlinois), L.S. Schroeder (Berkeley), L.C. Teng (Fermilab), E.W. Vogt (TRIUMF), and J.D. Walecka (Stanford). The conference is sponsored by the AUA Trust Fund, the Department of Energy, the National Science Foundation, Argonne, Brookhaven, Los Alamos, Berkeley, TRIUMF, Indiana University, and the University of Michigan. There will be some scholarships available to encourage younger scientists to attend. For further information, please contact the conference secretary: Mrs. Marion Heimerle, BIdg. 911B, Brookhaven National Laboratory, Upton, New York 11973, U.S.A., (516) 282-4776, Telex: 96-7703. 


\section{Financial Reports*}

Summary of Deposits and Expenses for the Barclays Bank Account

\section{Deposits}

Expenses

Total Deposits

Expenses :

Registration fee refunds:

(non-attendance)

Registration refunds given because of waivers:

Sheraton hotel deposits included with registration fees:

Check charges

Transfer to IntraWest to open account

Withdrawn for cashbox in Steamboat Springs

Miscellaneous office supplies:

Stamps and misc.

Timers

Airline guides

Stamps

Developing film

Financial assistance:

Total Expenses

Balance in Account (should be the same as checkbook balance)

* Prepare a report Iike this for each bank account. 
Sample Format

Summary of Receipts

Receipts Deposits

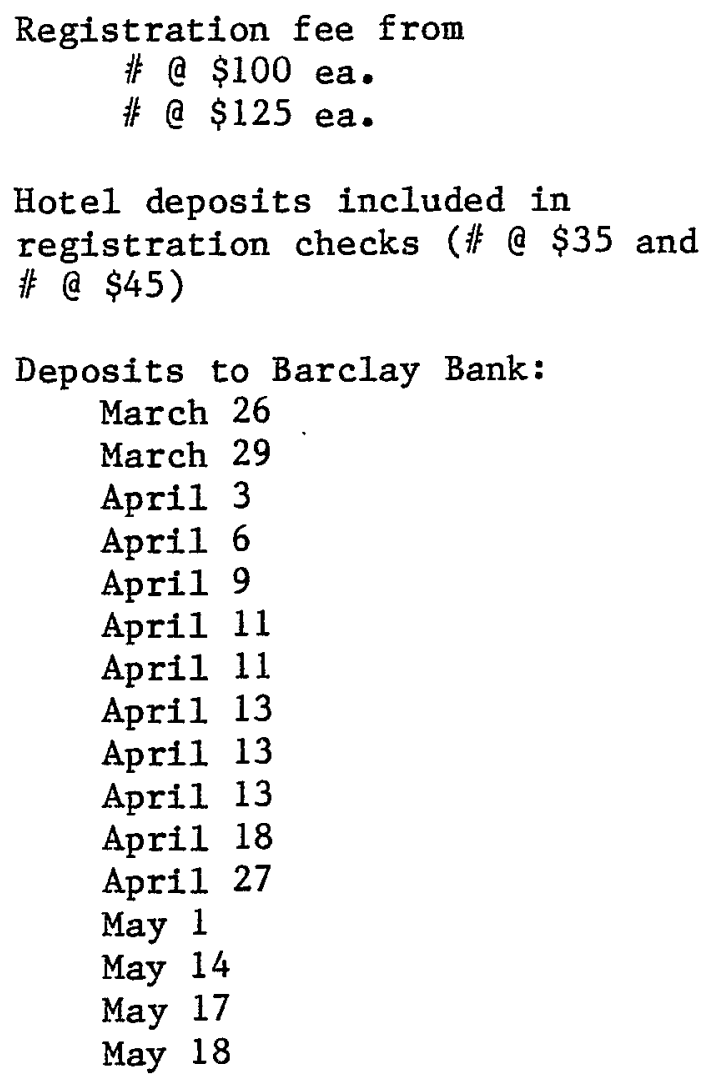

Hotel deposits included in

registration checks (非 @ \$35 and

\# @ \$45)

Deposits to Barclay Bank:

March 26

March 29

April 3

Apri1 6

Apri1 9

Apri1 11

April 11

Apri1 13

Apri1 13

Apri1 13

Apri1 18

Apri1 27

May 1

May 14

May 17

May 18

Total

(the total of each column should be equal)

(Xerox each check or traveler's check before depositing in the bank). Staple the deposit slip to the copies of the checks.) 


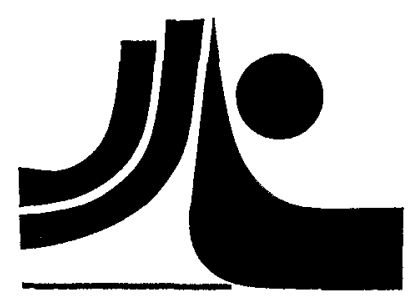

\section{CONFERENCE on the INTERSECTIONS between \\ PARTICLE and NUCLEAR PHYSICS May 23-30, 1984 \\ STEAMBOAT SPRINGS}

\section{ORGANIZING}
A.D. KRISCH Michigan (Go-chairman)
G.M. BUNCE Brookhaven
J.W. CRONIN Chicago
G.R. FARRAR Rutgers/Ins. Adv. Study
V.W. HUGHES Yale
T.D. LEE Columbia
T.A. O'HALLORAN Illinois
L.C. TENG Fermilab

\section{COMMITTEE}

\author{
M.H. MACFARLANE Indiana (co-chairman) \\ H.E. JACKSON Argonne \\ J.S. MCCARTHY Virginia \\ R.E. MISCHKE Los Alamos \\ E.J. MONIZ MIT \\ L.S. SCHROEDER Berkeley \\ E.W. VOGT TRIUMF
}

The Conference will be in the Sheraton at Steamboat Springs, Colorado. The Conference will stress Mutually Beneficial Cooperation between Particle And Nuclear Physics in Science, Technology, and Facilities; and will Highlight the Diversity and Importance of Particle And Nuclear Physics in the 1 to $100 \mathrm{GeV} / \mathrm{c}$ Region. There will be Plenary Talks and Parallel Sessions on:

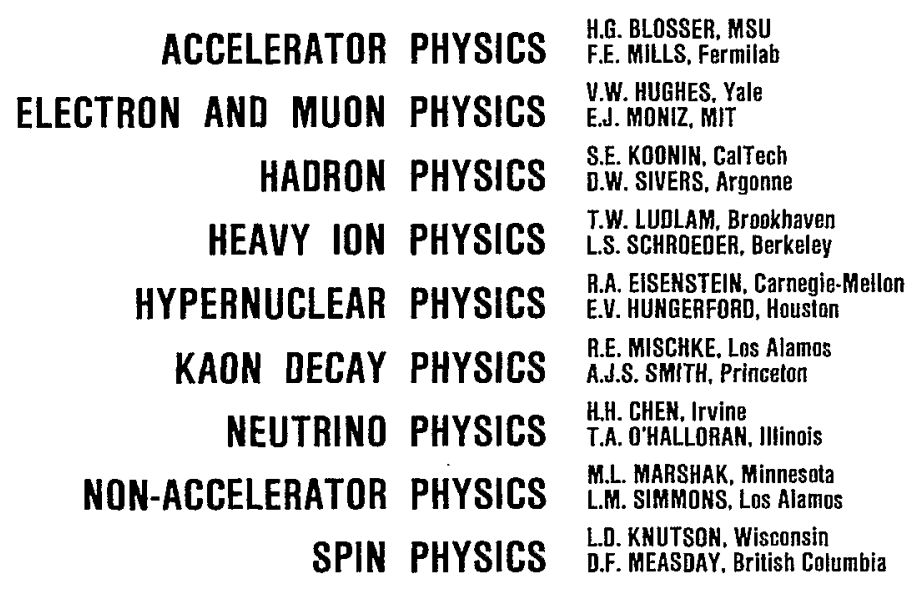

SPONSORED BY: AUA TRUST FUND, DEPT. OF ENERGY, NATIONAL SCIENCE FOUNDATION, ARGONNE, BERKELEY, BROOKHAVEN, LOS ALAMOS, TRIUMF, INDIANA UNIV., UNIV. OF MICHIGAN 
Organizing Committee

STEAMBOAT SPRINGS

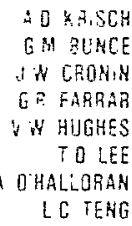

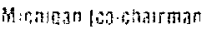
Broakhaven

Circagro

Putaers lns Adv Stut

Yale

Columbia

Hirings

Formilab
M M MACFARLANE
HE IACKSCA
IS MCCAPTHY
SE. MISCHKE
E J Makiz
IS SCHAOEDER
EW VGGT
J] WALECKA
Indianzicosharman
Armerzig
Vtriticia
Lns Alames
MIT
Berkeley
TRIUMF
Stantiont

Letter Acknowledging Receipt of Letter of Recommendation

April 3, 1984

Dear

We have recelved your request for financial assistance for the upcoming Conference on the Intersections between Particle and Nuclear Physics to be held in Steamboat Springs, Colorado on May 23-30, 1984.

Your request will be presented to the organizing committee and you will hear from them shortly.

Best regards,

Marion Heimerle

Conference Secretary

$\csc$ 
May 23-30, 1984

\section{Organizing Committee}

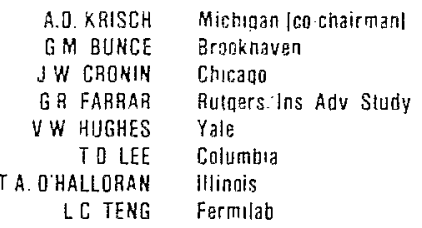
MH MACFARLANE H.E JACKSON JS. MC CARTHY RE MISCHKE EJ MONIZ LS. SCHROEDER E W VOGT J $D$ WALECKA
Indiana |co-chairman| Arqunn: Virqinia Los Alamos MIT Berkeley IRIUMF Staniord

Letter Informing Participant of Scholarship Award

Apri1 10, 1984

Dear

Thank you for your application for a "scholarship waiver" of the registration fee for the Conference on the Intersections between Particle and Nuclear Physics in Steamboat Springs this May.

We are very pleased to inform you that we are able to award you a scholarship waiver of the $\$ 100 / \$ 125$ registration fee.

We very much hope that this award will allow you to attend the conference and we look forward to seeing you in May.

Best regards,

\author{
M.H. Macfarlane \\ A.D. Krisch
}

$\csc$ 
May $23-30,1984$

Organizing Committes

\begin{tabular}{|c|c|}
\hline AO KRISCH & Michagan loo mharmant \\
\hline GH BUNCE & Bronkhaven \\
\hline JW CAOMIN & Cheage \\
\hline GR FARRAR & Rutçers. Ins Adv Study \\
\hline$\checkmark W$ HUGHES & Yale \\
\hline TOLEE & Columbia \\
\hline D HALLORAN & IIIInn!s \\
\hline LC TENG & Fermilab \\
\hline
\end{tabular}

WH MACFARLANE H.E JACKSCH IS MC RARTHY

AE MISCHKE E I MONIZ

LS SCHROEDER

EW VOGT

D. WALECKA

Indrana [co-zharman]

Arqune

Virguria

Los Alamos

MIT

Berkeley

TRUIMF

Stantard

\title{
Letter of Invitation for Spouses to Complimentary \\ Continental Breakfast at Conference
}

May 22, 1984

All spouses, children, and guests are invited to a complimentary continental breakfast on:

Wednesday May 25, 1984 at 9:15 am. in the Ante Room

There will be:

\author{
Fresh Orange Juice \\ Breakfast Pasteries \\ Coffee, Tea, Hot Chocolate, Milk
}

We hope that you take this opportunity to meet the other family and friends who are accompanying conference participants and to learn about our informal spouses program.

Best regards,

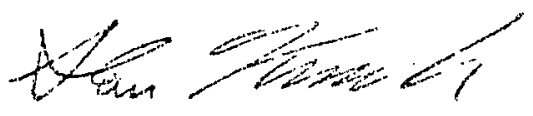

A.D. Krisch 
Letter of Invitation to Attend Conference (print on Conference letterhead, two-sided)

Dear Colleague:

We are writing to invite you to attend the

CONFERENCE on the INTERSECTIONS between PARTICLE and NUCLEAR PHYSICS May 23-30, 1984.

The Conference, which is open, will stress topics which are interesting to both particle and nuclear physicists. It will concentrate upon mutually beneficial cooperation between particle and nuclear physics in Science, Technology, and Facilities. Moreover, the Conference will highlight the diversity and importance of nuclear and particle physics in the 1 to $100 \mathrm{GeV} / \mathrm{c}$ range.

There will generally be colloquium-type talks each morning in the plenary sessions and about 5 parallel sessions each afternoon. There will be 9 different parallel sections on the topics of Accelerators, Electron and Muon Physics, Hadrons, Heavy Ions, Hypernuclear Physics, Kaon Decays, Neutrinos, Non-Accelerator Experiments, and Spin Physics. Each parallel section will have about 4 to 6 sessions of $1-1 / 2$ hours and will be run by the two coordinators listed on the enclosed announcement. Anyone wishing to make a contribution or suggest a topic, a speaker, or a discussion period should contact the appropriate coordinator, either directly or through the conference secretary. The Organizing Committee is now inviting some distinguished scientists to give the plenary lectures on major topics in a manner understandable to both the particle and nuclear physicists. Conference registration will be from 2:00 PM to 8:30 PM on Tuesday, May 22, 1984 and the Conference will end with a summary-type lecture at 7:00 PM on Wednesday, May 30, 1984. On most days there will be plenary lectures from 9:00 AM until 12:30 PM and parallel sessions from 3:30 PM to 7:00 PM. Saturday, May 26, 1984 will have morning parallel sessions and Sunday will be free.

The proceedings of the Conference will be published by the American Institute of Physics. Participants wishing to make short contributions will be sent information about the AIP format for contributions. Decisions about which contributions will be published will be made by the Organizing Committee and Dr. R.E. Mischke of Los Alamos, who has agreed to serve as Editor.

The Conference will be held at the "Sheraton at Steamboat." This is a very pleasant hotel in a mountain village near Steamboat Springs, Colorado at an elevation of about 6900 feet. The hotel complex includes very good conference rooms for plenary lectures and parallel sessions, about 300 hotel rooms, 
and several restaurants. There are a number of other hotels, condominiums, restaurants, and shops within 500 feet in "Steamboat Village," and many more facilities 2 miles away in the interesting old western town of Steamboat Springs.. The Sheraton has facilities for swimming, golf, tennis, hiking, horseback riding, and possibly downhill and cross-country skiing, and white water rafting, depending on the weather. Because this is their low season, they have offered us a very low rate of $\$ 35 /$ night single and $\$ 45 /$ night double for hotel rooms. Moreover, at this time the town will have few other visitors so that the informal and isolated atmosphere should offer an excellent opportunity for the particle and nuclear physicists to get to know each other better.

The registration fee will be $\$ 100$ if paid prior to April 6, 1984 and $\$ 125$ if paid at the Conference. This fee will include a copy of the proceedings and several conference functions. Please fill in and return as soon as possible the enclosed:

\section{Conference Registration Form and \\ Hotel Registration Form.}

A11 participants should guarantee their own hotel rooms by attaching a check made out to the hotel. Please use the enclosed envelope to return both forms and both checks (one check made out to CIPANP and one check made out to The Sheraton at Steamboat) to Marion Heimerle by April 6, 1984 so that we may process your forms and forward your hotel registration to The Sheraton at Steamboat by Apri1 22, 1984. Students and other young scientists may apply for a "scholarship" waiver of the registration fee by writing to Marion Heimerle and enclosing one letter of recommendation from their professor or supervisor.

We feel that this is a very exciting time in both nuclear and particle physics, with many new physics ideas being proposed and studied. We believe that our conference may make important contributions to both fields and we hope that you can attend and help us.

Best regards,

$$
\text { M.H. Macfarlane A.D. Krisch }
$$

$\csc$

Enc. 
CONFERENCE on the INTERSECTIONS bew

May 23-30, 1984

STEAMBOAT

SPRINGS

Orqanizing Committee

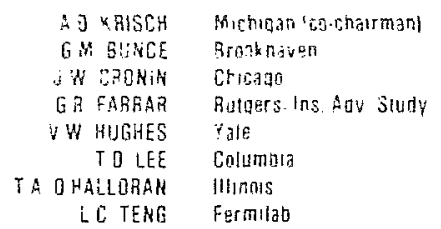
MU MACFARLAHE HE JACKSAH $J$ SO MCCARTHY
BE MISCHKE E.J जกNIZ LS SCHRBEOEA $E W: J G G T$ JO WALECKA
in Aronate पै। ios Alamos mit Berkeigy TRIIIMF Stantort

\section{Letter Requesting Parallel Session Coordinators Send to Conference} Secretary Copies of Their Correspondence

March 30, 1984

\section{Dear Session Coordinator:}

Alan Krisch and Malcolm Macfarlane would like to have a copy of any letters that you have written or will write inviting speakers to the upcoming Conference on the Intersections between Particle and Nuclear Physics. Please send the copies to me.

$$
\text { Sincerely yours, }
$$

Marion Heimerle

Conference Secretary

$\csc$

Enc. (10 return envelopes) 
'Letter to Participants to be Included in Participants' Packets

(Print on Conference Letterhead, two-sided)

Dear Participant:

Welcome to the Conference on the Intersections between Particle and Nuclear Physics. We hope that you will find the Conference productive, stimulating, and enjoyable.

You should find in your packet:

- Conference Schedule

-- Floor Plan of Meeting Rooms

- List of Participants

- Maps and Brochures of Steamboat Springs

-- Name Badge

-- Identification Label for Briefcase

-- Tickets for Social Functions

-- Travel Assistance Form.

The Conference Reception Desk will be open from 7:30 a.m. to 7:30 p.m. on weekdays and from 7:30 a.m. to $2 \mathrm{p} . \mathrm{m}$. on Saturday, May 26. Messages will be placed on a message board but if you are expecting any calls please let the conference staff know.

All properly typed manuscripts and signed AIP copyright forms should be turned in to Karen Poelakker who will be assisting Dr. Richard Mischke of Los Alamos in the editing of the proceedings.

Extra tickets for the Western Barbecue on Saturday, May 26, and/or the Banquet on Tuesday, May 29 can be purchased at the subsidized rate of $\$ 15$ each at the reception desk. The Barbecue will be appropriate for children and special tickets for the Barbecue will be available at $\$ 5$ each for children under 12. There will be no charge for friends and family members attending the Cocktail Parties and the Fruit, Cheese, and Wine Reception, but the complimentary tickets for these should be obtained in advance from the Conference Reception Desk.

Here in the Sheraton, Remington's Restaurant will be open as follows: $7 \mathrm{a} \cdot \mathrm{m} \cdot-11: 30 \mathrm{a} \cdot \mathrm{m}$. for Breakfast

$11: 30 \mathrm{a} \cdot \mathrm{m} .-2: 00 \mathrm{p} \cdot \mathrm{m}$. for Lunch

6:00 p.m.-10:00 p.m. for Dinner.

Also in the Sheraton, Buddy's Run, a cafeteria, will probably be open for breakfast from $7 \mathrm{a} \cdot \mathrm{m} .-10: 00 \mathrm{a} \cdot \mathrm{m}$. and the H. B. Longbaugh Bar will be open from 2:00 p.m. to midnight. There are many other restaurants in Steamboat Village and Steamboat Springs which are listed in the brochures and in the telephone book in your room. 
The Sheraton will cash personal checks for $\$ 50$ with Visa or Mastercard identification or personal checks for $\$ 100$ with an American Express Card. The hotel also has a safety deposit box for valuables. If you need help with foreign exchange, contact the Conference Reception Desk.

Please fill in your travel assistance form and return it to the Conference Reception Desk as soon as possible if you need airline flights changed or reconfirmed.

The Steamboat Taxi will take you to the Rocky Mountain Airways terminal in Steamboat. To obtain a taxi, please cal1 879-3111.

We hope that your experlence at the Conference will be a pleasant one. Please contact one of us if you have any questions or problems.

$$
\text { Cordially, }
$$

Chery1 Conrad, Brookhaven Joanne Day, Argonne June Goshi, Lawrence Berkeley Lorraine Gray, TRIUMF
Marion Heimerle, Brookhaven Roberta Marinuzzi, Los Alamos Karen Poelakker, Los Alamos Sue Streicher, Michigan 
Letter to Participants to be included in. Second Mailing

(Print on Conference letterhead, two-sided)

Dear Colleague:

We are very pleased that you plan to attend the

CONFERENCE on the INTERSECTIONS between PARTICLE and NUCLEAR PHYSICS May 23-30, 1984.

We are enclosing various information about the conference including:

1. Lists of the plenary speakers, topics, and chairman

2. A tentative schedule for the conference

3. A list of the coordinators of the parallel sessions

4. An AIP copyright form and the AIP format instructions.

5. A letter from the Sheraton hotel with some information about activities and transporation in Steamboat Springs

6. A transportation sheet

7. An extra hotel reservation card.

We are also pleased by the very interesting program of lectures, and by the many distinguished lecturers and participants who are planning to attend. We hope that these plenary lectures and the lectures and discussions in the parallel sessions will sharply focus attention on the importance and diversity of Nuclear and Particle physics in the region near 1 to $100 \mathrm{GeV} / \mathrm{c}$.

Participants who want to submit contributed papers should contact the appropriate coordinator (list enclosed) to see if there will be time for their contribution to be presented in the parallel sessions. The organizing committee attempted to transmit all suggestions of topics and contributions to the appropriate coordinator. However, we may have made some errors in choosing the most appropriate coordinator and we urge you to contact them yourself. Written versions of papers which are presented may be submitted for publication to Dr. R.E. Mischke of Los Alamos. Because of space limitations, paralle1 session papers will be limited to:

3 AIP pages for 10 minute papers

6 AIP pages for 20 minute papers

9 AIP pages for 30 minute papers.

Please try to have your paper typed according to the enclosed AIP format and bring it and the signed copyright form to steamboat. It may not be possible to include papers submitted later.

Registration will take place on Tuesday, May 22, 1984 from 1 p.m. until about $10 \mathrm{p} . \mathrm{m}$. In the Foyer of the Conference area of the hotel. Registration will also be possible on the following days. You will be given a packet of more detailed information about the conference and the Steamboat area at registration. 
There will be several social functions at the Conference including:

1. Cocktails at Registration on Tuesday, May 22

2. A Fruit, Cheese, and Wine Reception on Wednesday, May 23

3. A Western Barbecue on Saturday, May 26

4. A Cocktail Party and Banquet on Tuesday, May 29.

All these activities will be included in the registration fee for participants. Extra tickets for the Barbecue and/or Banquet for family members or friends can be purchased at the subsidized rate of $\$ 15$ each at registration. The Barbecue will be appropriate for children and special tickets for the Barbecue will be available at $\$ 5$ each for children under 12 . There will be no charge for friends and family members attending the Cocktail Parties and the Fruit, Cheese, and Wine Reception.

If you have not yet made your hotel reservations, we urge you to make them directly with the hotel immediately $(303-879-2220)$ as we have already passed the deadline and the hotel will no longer guarantee that space is avai1able. If you are arriving on Tuesday, May 22, you may have difficulty finding a seat on Rocky Mountain Airways from Denver to Steamboat because of their limited capacity. In this case you might consider renting a car in Denver in cooperation with other participants (Steamboat is about 160 miles northwest of Denver). Cheryl Conrad (516-282-4053) will try to help drivers and passengers get together if you telephone her with your exact flight arrival time in Denver.

We are looking forward to seeing you in Steamboat.

Best regards,

M.H. Macfarlane A.D. Krisch

csc

Enc. 
May 23-30, 1984

STEAMBOAT

SPRINGS
Organizing Committee

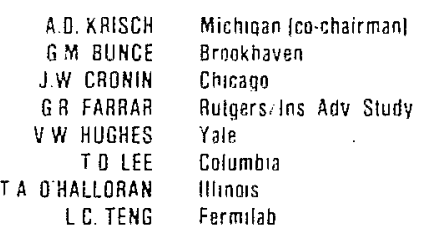
MH MACFARLANE HE JACKSGN IS MC CARTHY RE MISCHKE EJ MONIZ LS. SCHROEDER EW VOGT 1) WALECKA
Indiana log charmani Azqonite Virqirua Los Alamos MIT Berkelay TRIUMF Siantord

Letter to People Wanting Scholarships to Send

a Letter of Recommendation

March 19, 1984

Dear :

Thank you for your application for a "scholarship" waiver of the registration fee for the Conference on the Intersections between Particle and Nuclear Physics to be held in Steamboat Springs, Colorado on May 23-30, 1984.

Since we expect to receive more applications for these "scholarship" waivers than we can support, we would appreciate it if you could send us a letter of recommendation from your professor or supervisor. If this is not possible, please send us a copy of your resume.

The organizing committee will then be able to act on your application.

Best regards,

Marion Heimerle

Conference Secretary

$\csc$ 
May $23-30.4984$

STEAMBOAT SPRINGS
Orọanizınọ Cornmittee

\begin{tabular}{|c|c|}
\hline 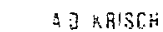 & Mchoan lco-chatrmag! \\
\hline IA SUMEE & Earkhoven \\
\hline ; $\mathrm{C}$ CROHIN & Cracagqo \\
\hline G F FARAAB & Rulqers ins âdv Sildy \\
\hline$\checkmark N$ HUGHES & Yal? \\
\hline$T D L E E$ & Colunta \\
\hline TA. OHALLORAN & 1113n:s \\
\hline L. C TENG & Formulab \\
\hline
\end{tabular}

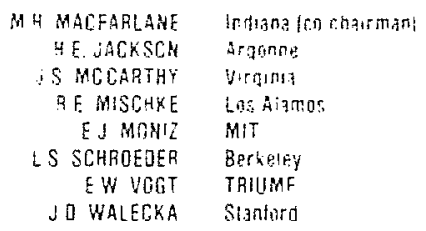

Letter-to Plenary Session Chairmen

(agreeing to chair a session)

Dear

We are writing to thank you for agreeing to chair a plenary session at the coming Conference on the Intersections between Particle and Nuclear Physics. The Conference will be held in the Sheraton Hotel in Steamboat Springs, Colorado from 9:00 a.m. on Wednesday, May 23, 1984 until 7:00 p.m. on Wednesday, May 30, 1984. We are enclosing some information about the Conference and would appreciate your filling in the enclosed forms and returning them in the enclosed envelope if you have not already sent in such forms.

We have not yet scheduled which session you will chair so if you have any special requests concerning dates or other considerations, please contact us as soon as possible.

We are able to offer you $\$$ to help cover your travel and living expenses while attending the Conference. We will also waive the $\$ 100$ Registration fee. We hope that you will be able to cover the remaining expenses from other sources.

We again thank you for agreeing to chair a session. We think that events in the past few years have clearly pointed to the need for closer cooperation between Nuclear and Particle physicists. We hope that this Conference may be a significant step in this cooperation, and we feel that your participation will help in this important process. We are looking forward to seeing you in May.

Best Regards,

\author{
M.H. Macfarlane A.D. Krisch
}

$\csc$

Enc. (initial mailing info) 
STEAMBOAT

SPRINGS
Grganizinọ Committes

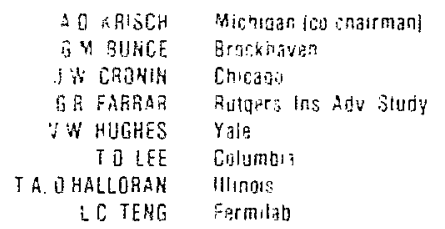

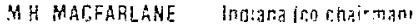
HE JACKSGA ATGGOA

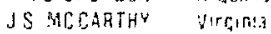
RE MISCHKE G.MAlamos
FJ MONIZ MIT
lS SCHRDEDER Barkelay
EW VGGT TRIIMF
I 0 WALECKA SLAnIORO

Letter to Plenary Speakers

(agreeing to give a lecture).

Dear

We are writing to thank you for agreeing to give a lecture at the coming Conference on the Intersections between Particle and Nuclear Physics. The Conference will be held in the Sheraton Hotel in Steamboat Springs, Colorado from 9:00 a.m. on Wednesday, May 23, 1984 until 7:00 p.m. on Wednesday, May 30, 1984. We are enclosing some information about the Conference and would appreciate your filling in the enclosed forms and returning them in the enclosed envelope if you have not already sent in such forms.

We plan to list the title of your lecture as:

and we have scheduled it for 20 minutes to be followed by 5 minutes of discussion. Please telephone or telex if this is not correct. The audience will be physicists from both Particle and Nuclear physics; thus a special effort should be made to make your lecture a colloquium-type talk understandable to a broad spectrum of physicists.

The proceedings of the Conference will be published by the American Institute of Physics with Dick Mischke of Los Alamos serving as Editor. Enclosed find an AIP format-form for your secretary and a copyright form to be signed by you and returned. We hope that you will submit a written version of your talk of up to pages at the time of the conference.

We are able to offer you $\$$ to help cover your travel and living expenses while attending the Conference. We will also waive the $\$ 100$ Registration fee. We hope that you will be able to cover the remaining expenses from other sources.

We again thank you for agreeing to give this lecture. We think that events in the past few years have clearly pointed to the need for closer cooperation between Nuclear and Particle physicists. We hope that this Conference may be a significant step in this cooperation, and we feel that your lecture will help in this important process. We are looking forward to seeing you in May。

Best Regards,

\author{
M.H. Macfarlane A.D. Krisch
}

$\csc$

Enc. (initial mailing info, AIP format + copyright form) 
CONFERENCE on the INTERSECTIONS between PARTICLE and NUCLEAR PHYSICS 44

May 23-30, 1984

Organizing Committee

$\begin{aligned} \text { A.D. KRISCH } & \text { Michigan [co-chairman] } \\ \text { G.M. BUNCE } & \text { Brookhaven } \\ \text { J.W. CRONIN } & \text { Chicago } \\ \text { G.R. FARRAR } & \text { Rutgers/Ins. Adv. Study } \\ \text { V.W. HUGHES } & \text { Yale } \\ \text { T.D. LEE } & \text { Columbia } \\ \text { A. O'HALL.ORAN } & \text { Illinois } \\ \text { L.C. TENG } & \text { Fermilab }\end{aligned}$

M.H. MACFARLANE H.E. JACKSON J.S. MC CARTHY

R.E. MISCHKE E.J. MONIZ L.S. SCHROEDER

E.W. VOGT

J.D. WALECKA
Indiana (co-chairman) Argonne

Virginia

Los Alamos MIT

Berkeley

ThIUMF

Marion Heimerle, Conference Secretary, Bldg. 911B, Brookhaven National Laboratory, Upton, L.I., N.Y., 11973 U.S.A. . 
Title

ข)

$e+\mu$

Spin

Hadron

Hadron

Hadron

Hadron

Hadron

Hadron

E.P. Co1ton/Los Alamos

Spin at Irvine

H.E. Conzett/Lawrence
R.C. Allen/Univ of Calif.

G.S. Anagnostatos/Nuclear Research Center, Greece

A.0. Barut/Univ of Colorado

A. Bodek/Univ of Rochester

E.A. Braaten/Argonne

R.L. Boudrie/LAMPF

M.K. Brussel/Univ. of IL

R.E. Chrien/Brookhaven

J.R. Comfort/Arizona State U

B.C. Clark/Ohio State Univ.

J. Cohen/Univ. of Virginia Berkeley Lab

Status of UCI/LAMPF Experiment E225

(Neutrino-Electron Elastic Scattering at the LAMPF Beamstop)

The proton and the neutron rms charge radii and the sizes of their bags

Relativistic Spin Physics from Field Theory and Spin-Resonances

Quarks in nuclei

An Upper Bound on the Proton-Delta Mass Difference in the Skyrme Model

Nuclear Physics Spectrometers at LAMPF II

Deep Inelastic $\left(1,1^{\prime}\right)$ Scattering for $3_{\mathrm{H} 1}$

Hypernuclear gamma rays

Reson Production in Nuclei

Anti-proton Nucleus Scattering and the Relativistic Impulse Approximation

1) Nuclear Renormalization Effects in Exclusive $(\pi, \pi N)$

2) The role of the rho-meson exchange in the response to spin-isospin proble and pionlike excitations in finite nuclei

Perhaps

A Topic on Spin Physics--MAYBE

*Update these lists and send copies of them to the parallel session coordinators about every 10 days along with updated lists of registrants. 
Conference on the Intersections Between Particle and Nuclear Physics

Steamboat Springs, Colorado
May $23-30,1984$

* SESSION COORDINATORS *

1. Accelerator Physics

Professor H.G. Blosser, Director

Cyclotron Laboratory

Michigan State University

East Lansing, MI 47724

(517) $355-9670$

2. Electron and Muon Physics

Professor V.W. Hughes

Department of Physics

Yale University

New Haven, CT 06511

(203) 436-3566

3. Hadron Physics

Professor S.E. Koonin

Department of Physics

California Institute of Technology

Pasadena, CA 91125

(213) $356-4586$

4. Heavy Ion Physics

Dr. T.W. Ludlam

Physics Department

Brookhaven National Laboratory

Upton, NY 11973

(516) 282-7968

5. Hypernuclear Physics

Professor R.A. Eisenstein

Department of Physics

Carnegie-Mellon University

Pittsburgh, PA 15213

(412) $578-2743$

6. Kaon Decay Physics

Dr. R.E. Mischke

LAMPF

Los Alamos National Laboratory

Los Alamos; NM 87545

(505) $667-6814$
Dr. F.E. Mills

Fermilab

P.0. Box 500

Batavia, IL 60510

(312) $840-3526$

Professor E.J. Moniz, Director

Bates Laboratory of Nuclear

Physics

Massachusetts Institute of

Technology

Cambridge, MA 02139

(617) 245-6600

Dr. D.W. Sivers

High Energy Physics Division

Argonne National Laboratory

Argonne, IL 60439

(312) $972-6208$

Dr. L.S. Schroeder

Department of Nuclear Science

Lawrence Berkeley Laboratory

Berkeley, CA 94720

(415) 486-7308

Professor E.V. Hungerford

Department of Physics

University of Houston

Houston, TX 77004

(713) $749-2834$
Professor A.J.S. Smith

Department of Physics

Princeton University

Princeton, NJ 08544

(609) 452-4395 
7. Neutrino Physics

Professor H.H. Chen

Department of Physics

The University of California

Irvine, CA 92717

(714) $856-6392$

8. Non-Accelerator Physics

Professor M.L. Marshak

Department of Physics

University of Minnesota

Minneapolis, MN 55455

(612) $373-0241$

9. Spin Physics

Professor L.D. Knutson

Department of Physics

University of Wisconsin

Madison, WI 53706 .

(608) 262-3096
Professor T.A. O'Halloran

Department of Physics

University of Illinois

Urbana, IL 61801

(217) $333-4392$

Dr. L.M. Simmons

T-Division

Los Alamos Scientific Laboratory

P.0. Box 1663

Los Alamos, NM 87545

(505) 667-5061

Professor D.F. Measday

Department of Physics

University of British Columbia

Vancouver, B.C. V6T $2 A 6$

CANADA

(604) 228-5098

mvh 
40 MINUTE + 60 MINUTE PLENARY TALKS

Name/Institution

R.H. Dalitz/Oxford

Title

R.K. Adair/Yale

Summary

K-Decay Physics

E.G. Adelberger/Univ. of Washington

G. Bunce/Brookhaven

J. Dawson/UCLA

G.R. Farrar/Inst. for Advanced Studies/Rutgers

D.F. Geesaman/Argonne

A.S. Goldhaber/SUNY at Stony Brook

J.H. Heisenberg/Univ. of New Hampshire

W. -Y. Lee/Columbia

H.J. Lipkin/Weizmann

Inst., Israel

J.W. Negele/MIT

D. Sinclair/University of Michigan

J.D. Walecka/Stanford

G. West/Los Alamos
Symmetry Violations in Nuclei

Hadron Physics

The Surfatron and Beat Wave Acceleration

Hadron Physics at High

Transverse Momentum

Nuclear Hadrodynamics

Seeking the Quark-Gluon Plasma

Electron Scattering Experiments

Neutrino Interactions

Quark Model Spectroscopy

Properties and Phases of Nuclear Matter

The Search for Proton Decay

Electroweak Interactions with Nuclei

The EMC Effect
May 15, 1984

Length

of Time

\# of

$60 \mathrm{~min}+$

10 Disc.

$40 \mathrm{~min}+$

10 Disc.

Thurs., May 24 $10: 45$ am

$40 \mathrm{~min}+$

Mon., May 28

$10: 45$ am

10 Disc.

Wed., May 23

$11: 35$ am

$40 \min +$

10 Disc.

Thurs., May 24

$40 \min +$

10 Disc.

$40 \min +$

Fri., May 25

10:45 am

10 Disc.

Fri., May 25

$40 \mathrm{~min}+$

10 Disc.

$40 \mathrm{~min}+$

Wed., May 23

10 Disc.

40 min +

10 Disc.

Fri.., May 25

9:25 am

40 min +

10 Disc.

$10: 45$ am

$40 \mathrm{~min}+$

10 Disc.

Tues., May 29

Mon., May 28

40 min +

10 Disc.

40 min +

Mon., May 28

10 Disc.

Wed., May 23

$40 \mathrm{~min}+$

10 Disc.

$\begin{array}{ll}\text { Tues, May } 29 & 40 \mathrm{~min}+ \\ \text { 11:35 am } & 10 \mathrm{Disc} \text {. }\end{array}$ 


\section{MINUTE PLENARY TALKS}

Name/Institution

P.D. Barnes /CarnegieMe1lon Univ.

W. Haeberli/Univ. of Wisconsin

L.G. Ratner/Brookhaven

Th. Walcher/CERN

G. Loew/SLAC

L.C. Teng/Fermilab

G.R. Young/Oak Ridge
Title

Hypernuclear Physics

Parity Experiments

Acceleration of Polarized

Protons at the AGS

p Physics at LEAR

\section{$\underline{\text { Date }}$}

Mon., May 28
9 am
Tues., May 29
9 am
Fri., May 25
9 am
Thurs., May 24
9 am

30 MINUTE PLENARY TALKS

\section{Title}

Electron Accelerators

High Intensity Proton Accelerators

Heavy Ion Colliders

Fri., May 25

Thurs., May 24

$11: 35$ am

Fri., May 25
Length

of Time

\# of

Pages

$20 \min +$

5 Disc.

$20 \min +$

5 Disc.

$20 \min +$

5 Disc.

$20 \min +$

5 Disc.

30 min +

5 Disc.

$30 \mathrm{~min}+$

12

5 Disc.

2:35 am 


\section{MINUTE INVITED TALKS}

\section{Name/Institution}

R.G. Arnold/SLAC and American University

P.T. Debevec/U, of I11.

P.F.M. Koehler/Fermilab

S.B. Kowalski/MIT

J.S. McCarthy/Virginia

R.B. Palmer/Brookhaven

N.P. Samios/Brookhaven

L.S. Schroeder/Berkeley

H.A. Thiessen/Los Alamos

E.W. Vogt/TRIUMF
Title

SLAC NPAS Electron Facility

Illinois Electron Facility

Facilities at Fermilab

MIT Bates Electron Facility

SURA Electron Accelerator

AGS II

Brookhaven Heavy Ion Collider

Berkeley Heavy Ion Program

LAMPF II

TRIUMF Kaon Factory
Date

Fri., May 25

$6: 30 \mathrm{pm}$

Fri., May 25

$5 \mathrm{pm}$

Fri., May 25

$6 \mathrm{pm}$

Fri., May 25

4:30 pm

Fri., May 25

$4 \mathrm{pm}$

Fri., May 25

4:30 pm

Fri., May 25

6:30 pm

Fri., May 25

$6 \mathrm{pm}$

Fri., May 25

$4 \mathrm{pm}$

Fri., May 25

$5 \mathrm{pm}$
Length

of Time

25 min +

5 Disc.

$25 \min +$

5 Disc.

$25 \min +$

5 Disc.

$25 \min +$

5 Disc.

$25 \min +$

5 Disc.

$25 \mathrm{~min}+$

5 Disc.

$25 \min +$

5 Disc.

$25 \min +$

5 Disc.

$25 \mathrm{~min}+$

5 Disc.

$25 \mathrm{~min}+$

5 Disc.
\# of

Pages 


\section{SESSION CHAIRMEN}

Name/Institution

0. Chamberlain/Berkeley

B. Cork/Lawrence Berkeley Lab

M. Deutsch/MIT

H. Feshbach/MIT

G. Fidecaro/CERN

G.S. Goldhaber/Brookhaven

E. Hayward/Nat. Bureau of Standards

A.D. Krisch/Univ. of Michigan

M.H. Macfarlane/Indiana Univ.

L. Rosen/LAMPF

R.G. Sachs/University of Chicago

D.R. Yennie/Cornel1 University $\underline{\text { Date }}$

Wed., May 23

morning

Fri., May 25

early afternoon

Tues., May 29

morning

Wed., May 30

afternoon

Thurs., May 24

morning

Fri., May 25

early morning

Mon., May 28

morning

Fri., May 25

late af ternoon

Proton \& Heavy Ion

Fri., May 25

late afternoon

Electron \& Fermilab

Wed., May 23

afternoon

Wed., May 30

morning

Fri., May 25

late morning 


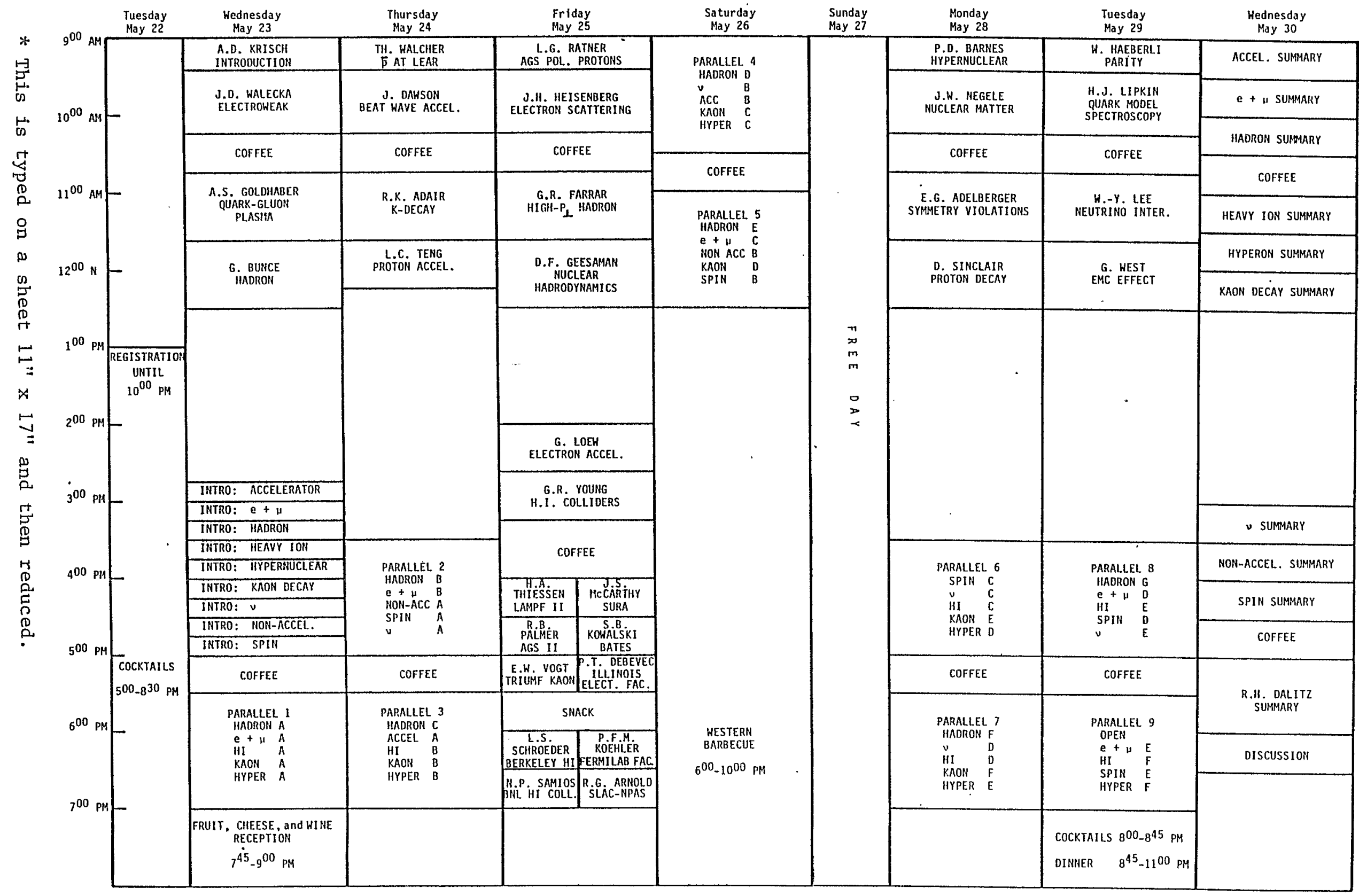




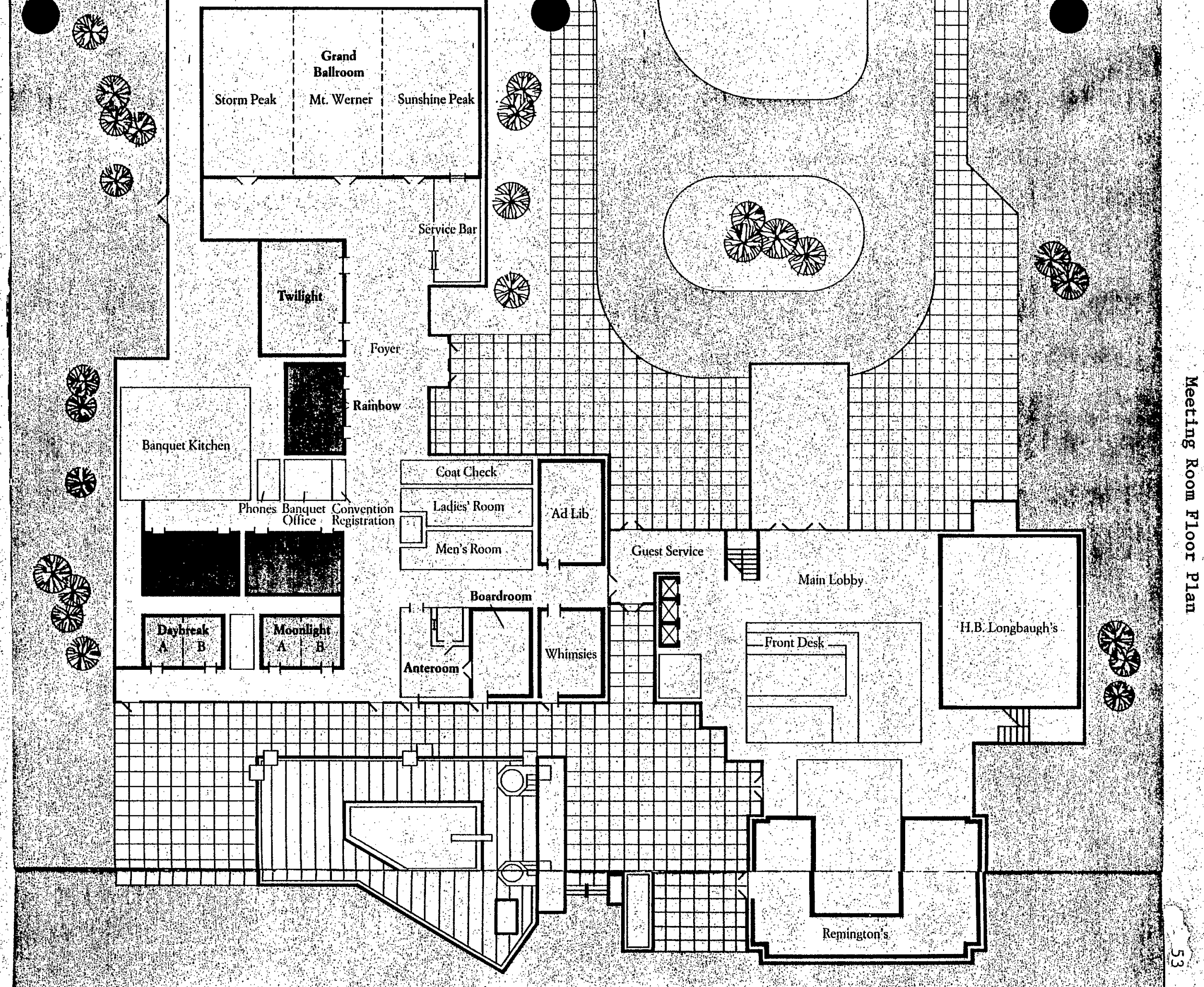


Sample*

Parallel Session Schedule

CONFERENCE ON THE INTERSECTIONS BETWEEN PARTICLE AND NUCLEAR PHYSICS

The Sheraton at Steamboat Springs, Colorado

May 23-30, 1984

Accelerator Parallel Session

Coordinator: F.E. Mills

Thursday, May $24-3: 30 \mathrm{pm}$ - Parallel 3 - Storm Peak

S. Ohnuma Effects of nonlinear elements in synchrotron lattices

R. Pollock Cooling rings for nuclear physics

Saturday, May 26-9:00 am - Paralle1 4 - Mt. Werner

P. Morton Novel accelerator concepts

A. Ruggiero Intrabeam scattering in beam storage devices

E. Colton Longitudinal tune control in synchrotrons

* Prepare a schedule for each parallel session. Get the information from the parallel session coordinators a few weeks before the conference. Print them before hand and ship to the conference location. 
May' 23-30. 1984

Orạnizing Con mititec

A D REISCH

G.M ELIREE

J.K. CFOhIK

GR. FARART

$\checkmark$ W. HUGHES

T.D. LEE

TA. OHALLOAFH

L. TENG

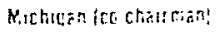
Ereokticuse

Chisege

Rutque Ine hov Entit

Yaie

Columbia

lllinals

Fernitat:
M. M MACFAELARE

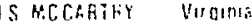
fe Mischire los hlatia.
EJ Mithit $M$ it
: S SCHFocots Entioley
EW JrG Thlumi

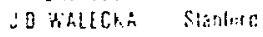

(Master)

Schedule for Parallel Sessions

Sunshine

Peak

Wed., líay 23 Par 1

Thurs., May 24 Par 2

Par 3

Sat., May 26

Par 4

Par 5

Mon., Ney 28

$\operatorname{Par} 6$

Par 7

Hadron/A

Hadron/B

Hadron/C

$\mathrm{e}+\mu / \mathrm{B}$

Acc/A

Hadron/D

$v / \mathrm{B}$

Hadron/E

$\mathrm{e}+\mu / \mathrm{C}$

$\mathrm{Spin} / \mathrm{C}$

Hadron/F

$v / C$

$v / D$.

Hadron/G

OPEN $\mathrm{e}+\mu / \mathrm{D} \quad \mathrm{HI} / \mathrm{E}$

$\mathrm{e}+\mu / \mathrm{E} \quad \mathrm{HI} / \mathrm{F}$
Mt.

Werner Twilight Rainbow

$\mathrm{HI} / \mathrm{A}$

Non Acc/A

$\mathrm{HI} / \mathrm{B}$

$\mathrm{K} / \mathrm{A}$

Hyper/A

Acc/B

$\mathrm{HI} / \mathrm{C}$

$\mathrm{HI} / \mathrm{D}$
$\mathrm{K} / \mathrm{E}$

$\mathrm{K} / \mathrm{F}$

Spin/D

$\operatorname{Spin} / \mathrm{E}$

$v / A$

Hyper/B

$\mathrm{K} / \mathrm{B}$

$\mathrm{K} / \mathrm{C}$

Hyper/C

$\mathrm{Spin} / \mathrm{B}$

Hyper/D

Hyper/E

$v / E$

Hyper/F

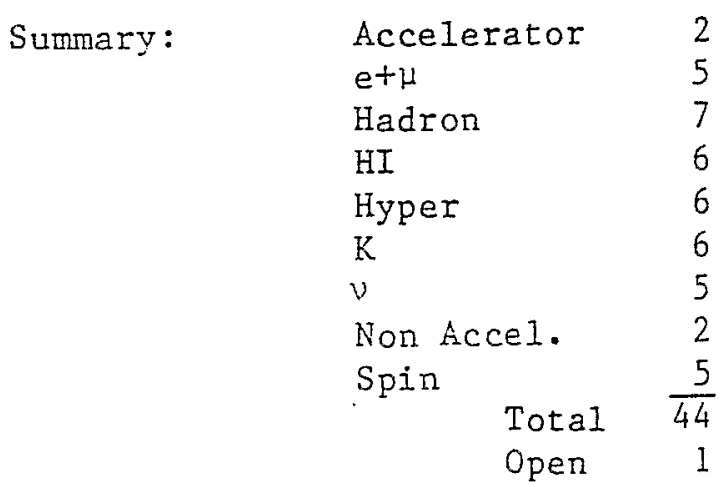




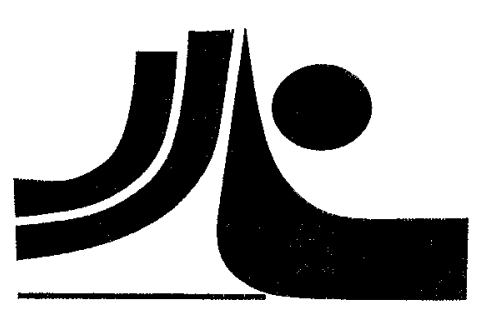

\section{CONFERENCE on the INTERSECTIONS between \\ PARTICLE and NUCLEAR May 23-30, 1984 \\ STEAMBOAT SPRINGS
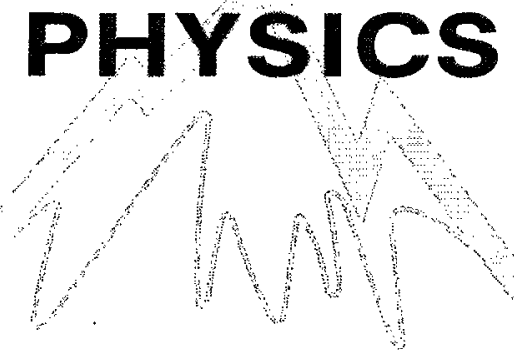 \\ ORGANIZING \\ A.D. KRISCH Michigan (co-chairman) \\ G.M. BUNCE Brookhaven \\ J.W. CRONIN Chicago \\ G.R. FARRAR Rutgers/Ins. Adv. Study \\ V.W. HUGHES Yale \\ T.D. LEE Columbia \\ T.A. O'HALLORAN IIlinois \\ L.C. TENG Fermilab \\ COMMITTEE \\ M.H. MACFARLANE Indiana [co-chairman] H.E. JACKSON Argonne \\ J.S. MC CARTHY Virginia \\ R.E. MISCHKE Los Alamos \\ E.J. MONIZ MIT \\ L.S. SCHROEDER Berkeley \\ E.W. VOGT TRIUMF \\ J.D. WALECKA Stanford}

The Conference will be in the Sheraton at Steamboat Springs, Colorado. The Conference will stress Mutually Beneficial Cooperation between Particle And Nuclear Physics in Science, Technology, and Facilities; and will Highlight the Diversity and Importance of Particle And Nuclear Physics in the 1 to $100 \mathrm{GeV} / \mathrm{c}$ Region. There will be Plenary Talks and Parallel Sessions on:

\begin{tabular}{|c|c|c|}
\hline ACCELERATOR & PHYSICS & $\begin{array}{l}\text { H.G. BLOSSER, MSU } \\
\text { F.E. MILLS. Fermilab }\end{array}$ \\
\hline ECTRON AND MUON & PHYSICS & $\begin{array}{l}\text { V.W. HUGHES, Yale } \\
\text { E.J. MONIZ, MIT }\end{array}$ \\
\hline HADRON & PHYSICS & $\begin{array}{l}\text { S.E. KOONIN, EalTech } \\
\text { D.W. SIVERS, Arganne }\end{array}$ \\
\hline HEAVY ION & PHYSICS & $\begin{array}{l}\text { T.W. LUDLAM, Brookhaven } \\
\text { L.S. SCHROEDER, Berkel ey }\end{array}$ \\
\hline HYPERNUCLEAR & PHYSICS & $\begin{array}{l}\text { R.A. EISENSTEIN. Carnegie-Mellon } \\
\text { E.U. HUNGERFORD, Houston }\end{array}$ \\
\hline KAON DE & PHY & $\begin{array}{l}\text { R.E. MISCHKE, Los Alamas } \\
\text { A.J.S. SMITH, Princeton }\end{array}$ \\
\hline NFI & PHYSICS & $\begin{array}{l}\text { H.H. CHEN. Irvine } \\
\text { T.A. O'HALLORAN. Illinois }\end{array}$ \\
\hline . & & $\begin{array}{l}\text { M.L. MARSHAK, Minnesota } \\
\text { L.M. SIMMONS. Los Alamos }\end{array}$ \\
\hline 0 & PHYSICS & $\begin{array}{l}\text { L.D. KNUTSON, Wiscansin } \\
\text { D.F. MEASDAY, British Columbia }\end{array}$ \\
\hline
\end{tabular}

SPONSORED BY: AUA TRUST FUND, DEPT. OF ENERGY, NATIONAL SCIENCE FOUNDATION, ARGONNE, BERKELEY, BROOKHAVEN, LOS ALAMOS, TRIUMF, INDIANA UNIV., UNIV. OF MICHIGAN 
CONFERENCE ON THE INTERSECTIONS BETWEEN PARTICLE AND NUCLEAR PHYSICS

The Sheraton at Steamboat Springs, Colorado

May 23-30, 1984

numbered
RECEIPT
Date

RECEIVED FROM:

AFFILIATION :

REGISTRATION FEE

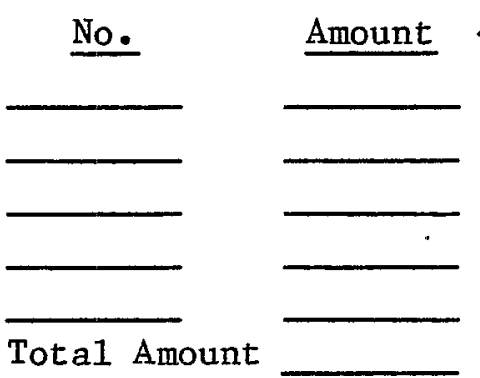

Conference Representative

(three part NCR form)

$\left(8 \frac{1}{2} \times 5 \frac{1}{2}\right)$

Office Use Only

Method of Payment: Cash Check Travelers Checks 
CONFERENCE ON THE INTERSECTIONS BETWEEN PARTICLE AND NUCLEAR PHYSICS

The Sheraton at Steamboat Springs, Colorado

May 23-30, 1984

REGISTRATION FORM

NAME: Prof./Dr./Mr./Ms. Last First , M.I.

AFFILIATION:

MAILING ADDRESS:

TELEPHONE (With Area Code):

TELEX:

Please check and return:

Plan To Attend

Might Attend

Plan Not To Attend

$\$ 100$ Registration Fee Enclosed. Make check payable to the Conf. on

Intersections between Particle and Nuclear Physics (CIPANP).

Will Pay $\$ 125$ Registration Fee Upon Arrival

Wil1 Be Accompanied By

(Extra tickets for social events can be purchased.)

Plan To Share A Room With

Arrival Date:

Departure Date:

Please mail this completed form and the registration fee before Apr. 6, 1984

to: Mrs. Marion Heimerle, Conference Secretary

B1dg. 911B, Brookhaven National Laboratory

Upton, NY 11973 USA

[(516) 282-4776; Telex: 96-7703]

Please use the enclosed envelope to return both this form and the hotel registration card.

Plan To Contribute A Paper--Please Send in Attached Abstract Form

Subject of paper:

Suggested speakers, topics, or other comments: 
(printed on green paper)

CONFERENCE ON THE INTERSECTIONS BETWEEN PARTICLE AND NUCLEAR PHYSICS
The Sheraton at Steamboat Springs, Colorado
May 23-30, 1984

SOCIAL ACTIVITIES QUESTIONNAIRE

yes

$\underline{\text { no }}$

Do you plan to attend the Fruit, Cheese, and Wine Reception

on Wednesday, May 23 ?

$(7: 45-9: 00 \mathrm{pm})$

I will bring guests to the Reception.

(There is no charge for this but tickets are needed.)

Do you plan to attend the Western Barbecue on Sat., May 26? (6:00-10:00 pm)

I will bring guests to the Western Barbecue.

(Tickets are $\$ 15$ for adults and $\$ 5$ for children under 12.)

Do you plan to attend the Banquet on Tuesday, May 29 ?

(Cocktails 8:00-8:45 pm, Dinner 8:45-11:00 pm)

I will bring guests to the Banquet.

(Tickets are $\$ 15$ each for the Banquet. There is no charge for cocktails but tickets are needed.) 
CONFERENCE ON THE INTERSECTIONS BETWEEN PARTICLE N NUCLEAR PHYSICS

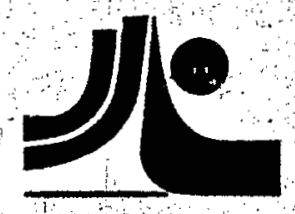

Good for one Cocktait

on Tuesday May 22, 1984

(Yellow)

CONFERENCE ON THE INTERSECTIONS

BETWEEN PARTICLE \& NUCLEAR PHYSICS

Reception

Wednesday May 23,1984

$(r \in d)$

CONFERENCE ON THE INTERSECTIONS BETWEEN PARTICLE \& NUCLEAR PHYSICS

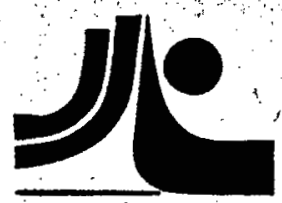

Good for One Glass of Beer on Saturday May 26, 1984

(beige)
CONFERENCE ON THE INTERSECTIONS BETWEEN PARTICLE \& NUCLEAR PHYSICS

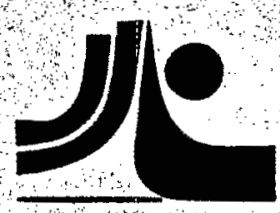

Western Barbecue

Saturday May 26,1984

(green)
Good for One Cocktail on Tuesday May 29, 1984

(blue)
CONFERENCE ON THE INTERSECTIONS BETWEEN PARTICLE \& NUCLEAR PHYSICS

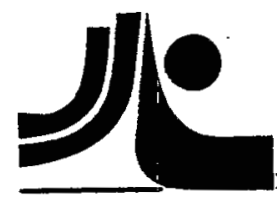

Banquet

Tuesday May 29, 1984

(white)
CONFERENCE ON THE INTERSECTIONS BETWEEN PARTICLE \& NUCLEAR PHYSICS

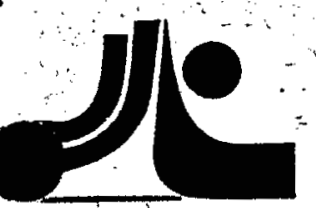

Good for One Glass of Beer on Saturday May 26, 1984

(beige) 
CONFERENCE ON THE INTERSECTIONS

BETWEEN PARTICLE \& NUCLEAR PHYSICS

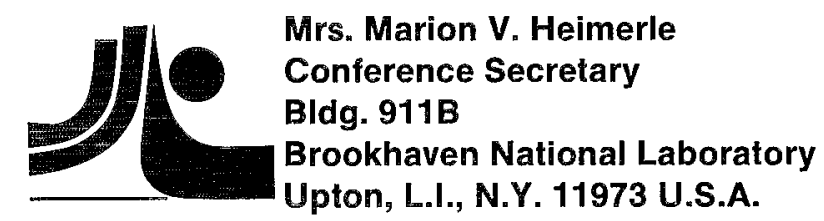

This sticker was used as return labels. 
Transportation Sheet

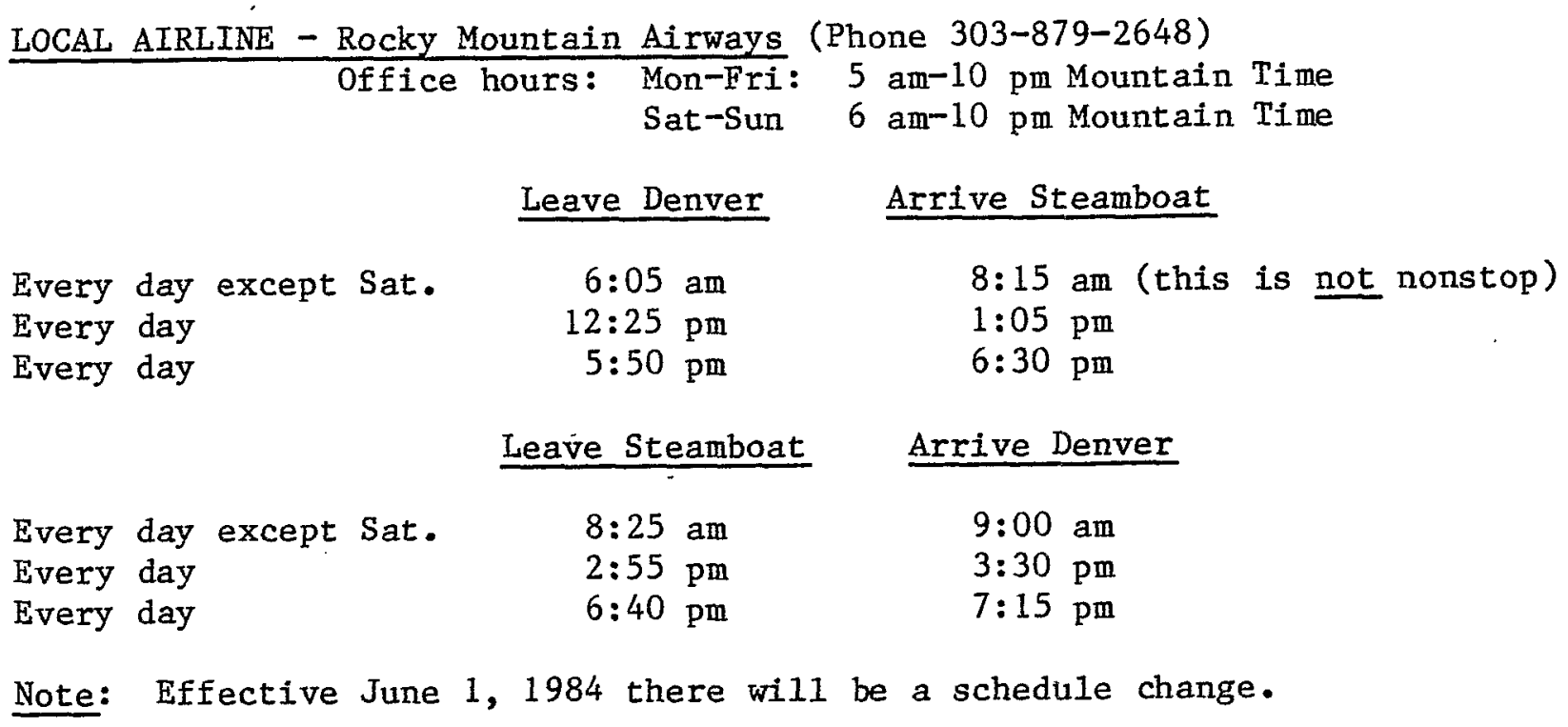

TRAILWAYS BUS (Phone 303-879-4997)

Office hours: $5: 30 \mathrm{am}-10$ am and $1: 00 \mathrm{pm}-6 \mathrm{pm}$

Leave Denver Arrive Steamboat

Every day

$12: 30$ am

$5: 20$ am

Every day

$12: 45 \mathrm{pm}$

5:25 pm

Leave Steamboat Arrive Denver

Every day
$12: 55$ am
$2: 15 \mathrm{pm}$
$5: 30 \mathrm{am}$
$7: 30 \mathrm{pm}$

The bus depot is located in Fish Creek Park, East Highway 40, Steamboat

Springs. To get to the bus depot, take the RTD City Bus.

\section{HOTELS/MOTELS NEAR THE AIRPORT}

Clarion Hote1--Denver Airport, 3203 Quebec Street, 303-321-3333

Hilton Inn--Airport, 4411 Peoria Street, 303-373-5730

Rodeway Inn-Airport, 4590 Quebec Street, 303-320-0260

Sheraton--Denver Airport, 3535 Quebec Street, 303-333-7711

Stapleton Plaza Hotel, 3333 Quebec Street, 303-321-3500

RENTAL CARS-AII major rental car companies

$$
\begin{gathered}
\text { Price Range } \\
\$ 60-94 \\
\$ 54-98 \\
\$ 48-64 \\
\$ 57-91 \\
\$ 70-84
\end{gathered}
$$


Hotel Room No.

(this no. will be given to your airline)

1. I already hold the following confirmed reservation(s) which should be (check one):

A. reconfirmed

B. changed to new reservation (refer to Item 2 below)

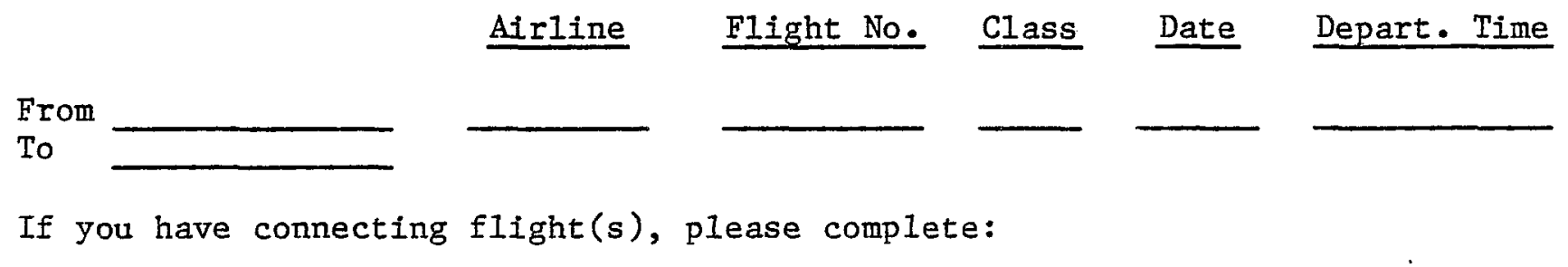

Airline Flight No. Class Date Depart. Time

From

To

From

To

2. I want to have a new reservation confirmed as follows (if you hold a ticket issued at a restricted fare, please advise or attach your ticket):

my ticket is attached

my ticket is not attached

3. I would like to share a rental car from Steamboat to Denver leaving Steamboat on (date) , at around (time)

I would prefer to be a:

$$
\text { driver }
$$

passenger

Conference Staff Reply:

Your reservation has been confirmed/reconfirmed/changed by on 
Appendix 1: Conference Participants 
Conference Participants

Robert K. Adair

Eric G. Adelberger

Lewis Agnew

Richard C. Allen

James Amman

Jurgen Arends

Raymond G. Arnold

Andrew Bacher

Helmut W. Baer

Peter D. Barnes

Asim 0. Barut

Bernd Basselleck

Eugene W. Beier

Tarlochan S. Bhatia

David H. Boal

Arie Bodek

Arnold R. Bodmer

Richard L. Boudrie

Theodore Bowen

Charles D. Bowman

J. David Bowman

James N. Bradbury

Douglas A. Bryman

Gerry Bunce

George R. Burleson

Roger D. Carlini

Peter Carruthers

Owen Chamberlain

Chia-Cheh Chang

Herbert $\mathrm{H}$. Chen

Robert E. Chrien

Bunny C. Clark

Rick Coleman

Eugene P. Colton

Joseph R. Comfort

Homer $\mathrm{E}$. Conzett

Bruce Cork

Stephen R. Cotanch

Pierre Couvert

Ha11 Crannel1

Kenneth M. Crowe

Richard H. Dalitz

Jay C. Davis

Raymond Davis

Norman E. Davison

John M. Daws on

Paul T. Debevec
Yale University

University of Washington

Los Alamos National Laboratory

University of California at Irvine

Los Alamos National Laboratory

Catholic University of America

American University

Indiana University

Los Alamos National Laboratory

Carnegie-Mellon University

University of Colorado

University of New Mexico

University of Pennsylvania

Los Alamos National Laboratory

Michigan State University

University of Rochester

Argonne National Laboratory

Los Alamos National Laboratory

University of Arizona

Los Alamos National Laboratory

Los Alamos National Laboratory

Los Alamos National Laboratory

TRIUMF

Brookhaven National Laboratory

New Mexico State University

Los Alamos National Laboratory

Los Alamos National Laboratory

Lawrence Berkeley Laboratory

University of Maryland

University of California at Irvine

Brookhaven National Laboratory

Ohio State University

Fermilab

Los Alamos National Laboratory

Arizona State University

Lawrence Berkeley Laboratory

Lawrence Berkeley Laboratory

North Carolina State University

TRIUMF/University of British Columbia

National Science Foundation

Lawrence Berkeley Laboratory

Oxford University

Lawrence Livermore National Laboratory

Brookhaven National Laboratory

University of Manitoba

University of California at Los Angeles

University of Illinois' at Champaign 
Pierre H. Depommier Ni G. Deshpande Martin Deutsch Thomas W. Dombeck Joey B. Donahue Jacob Doornbos

Robert A. Eisenstein Steve R. Elliott Martin B. Epstein John R. Erskine

Glennys R. Farrar Harold W. Fearing Herman Feshbach Giuseppe Fidecaro Daniel H. Fitzgerald Terry H. Fortune Sun-Yiu S. Fung Herbert 0. Funsten

Gerald T. Garvey Anibal 0. Gattone Donald F. Geesaman William R. Gibbs Benjamin F. Gibson Charles M. Glashausser George Glass

Alfred S. Goldhaber Gertrude S. Goldhaber Paul Goldhammer Terry J. Goldman George Gollin Richard Grace John F. Greenhalgh Franz L. Gross Willy Gruebler

Willy Haeberli Donald C. Hagerman Alan A. Hahn Aksel L. Hallin P. Haridas Malcolm Harvey Wick C. Haxton Evans V. Hayward Jochen H. Heisenberg Leon Heller

Dave Hendrie Peter Herczeg Russel1 G. Herron Andrew S. Hirsch
University of Montreal

University of Oregon

Massachusetts Institute of Technology

Los Alamos National Laboratory

Los Alamos National Laboratory

TRIUMF

Carnegie-Mel1on University

University of California at Irvine

California State University at Los Angeles

U.S. Department of Energy

Inst. for Adv. Studies/Rutgers University TRIUMF

Massachusetts Institute of Technology CERN

Los Alamos National Laboratory

University of Pennsylvania

University of California at Riverside

College of William \& Mary

Argonne National Laboratory

Indiana University

Argonne National Laboratory

Los Alamos National Laboratory

Los Alamos National Laboratory

Rutgers University

Texas A\& M University

State University of NY at Stony Brook

Brookhaven National Laboratory

University of Kansas

Los Alamos National Laboratory

Princeton University

Carnegie-Mellon University

Princeton University

College of William \& Mary

ETH Zurich

University of Wisconsin

Los Alamos National Laboratory

University of California at Irvine

Los Alamos National Laboratory

Massachusetts Institute of Technology

Chalk River Nuclear Laboratory

Los Alamos National Laboratory

National Bureau of Standards

University of New Hampshire

Los Alamos National Laboratory

Lawrence Berkeley Laboratory

Los Alamos National Laboratory

St. John's Seminary College

Purdue University 
Gloria T. Hoff

Cyrus M. Hoffman

Barry Holstein

Roy Holt

Arnold Honig

Charles J. Horowitz

Robert $E$. Hughes

Ed V. Hungerford

W-Y. Pauchy Hwang

George J. Igo

Kenichi Imai

William W. Jacobs

John J. Jarmer

Chueng R. Ji

Mikkel B. Johnson

Mohan S. Kalelkar

Alvin S. Kanofsky

Rainer Kaps

Kirby W. Kemper

Fatah-Zouhir Khiari

W. Wayne Kinnison

Paul N. Kirk

Leonard Kisslinger

Yoshihisa Kitazawa

James N. Knudson

Lynn D. Knutson

Che Ming Ko

D.H. Koang

Peter F.M. Koehler

John R. Kogut

Steven E. Koonin

Stanley Kowalski

Alan D. Krisch

Ray Kunselman

George P. Lawrence

Wen-Piao Lee

Wonyong Lee

Michael J. Leitch

Edward J. Levins on

Philip Levy

B. Joseph Lieb

Harry J. Lipkin

Donald E. Lobb

Gregory A. Loew

Earle L. Lomon

Derek I. Lowenstein

Thomas W. Ludlam
University of Illinois at Chicago

Los Alamos National Laboratory

University of Massachusetts at Amherst

Argonne National Laboratory

Syracuse University

Massachusetts Institute of Technology

Associated Universities, Inc.

University of Houston

Indiana University

University of California at Los Angeles

Kyoto University

Indiana University

Los Alamos National Laboratory

Stanford Linear Accelerator Center

Los Alamos National Laboratory

Rutgers University

Lehigh University

Michigan State University

Florida State University

University of Michigan

Los Alamos National Laboratory

Louisiana State University

Carnegie-Mellon University

University of Chicago

Arizona State University

University of Wisconsin

Texas A \& M University

Institut des Sciences Nucleaires

Fermilab

University of Illinois at Urbana

California Institute of Technology

Massachusetts Institute of Technology

University of Michigan

University of Wyoming

Los Alamos National Laboratory

TRIUMF/University of Manitoba

Columbia University

Los Alamos National Laboratory

Simon Fraser University

TRIUMF

George Mason University

Weizmann Institute of Science

TRIUMF/University of Victoria

Stanford Linear Accelerator Center

Massachusetts Institute of Technology

Brookhaven National Laboratory

Brookhaven National Laboratory 
William M. MacDonald

Robert J. Macek

Malcolm H. Macfarlane

Hay B. Mak

Alfred K. Mann

Daniel R. Marlow

Marvin L. Marshak

James S. McCarthy

Joseph P. McDermott

David F. Measday

John Millener

David J. Miller

Warren Miller

Fred E. Mills

Cas Milner

Richard E. Mischke

Ernest J. Moniz

Hugh Montgomery

George C. Morrison

Phil Morton

Gordon S. Mutchler

Fred Myhrer

Darragh Nagle

Kozi Nakai

Subrata Nath

John W. Negele

Lee C. Northcliffe

Thomas A. O'Halloran

Shoroku Ohnuma

Lorne A. Page

Robert B. Palmer

David C. Peaslee

Jen-Chieh Peng

Victor Perez-Mendez

Bruce A. Peterson

Gerald C. Phillips

Eliazer Piasetzky

Philip H. Pile

Lawrence S. Pinsky

Robert Pollock

Car1 H. Poppe

John P. Ralston

Ronald D. Ransome

Lazarus G. Ratner

Richard C. Raymond

Robert P. Redwine

Clarence R. Richardson

Jack L. Ritchie

Hans Georg Ritter
University of Maryland

Los Alamos National Laboratory

Indiana University

Queen's University

University of Pennsylvania

Carnegie-Mellon University

University of Minnesota

University of Virginia

University of Colorado at Boulder

University of British Columbia

Brookhaven National Laboratory

University College, London

Los Alamos National Laboratory

Fermilab

Los Alamos National Laboratory

Los Alamos National Laboratory

Massachusetts Institute of Technology

Fermilab

University of Birmingham, England

Stanford Linear Accelerator Center

Rice University

University of South Carolina

Los Alamos National Laboratory

University of Tokyo

Texas A \& M University

Massachusetts Institute of Technology

Texas A\& M University

University of Illinois at Urbana

Fermilab

University of Pittsburgh

Brookhaven National Laboratory

University of Maryland

Los Alamos National Laboratory

Lawrence Berkeley Laboratory

University of Wyoming

Rice University

Los Alamos National Laboratory

Brookhaven National Laboratory

University of Houston

Indiana University

Lawrence Livermore National Laboratory

Argonne National Laboratory

Max-Planck Institute

Brookhaven National Laboratory

University of Michigan

Massachusetts Institute of Technology

U.S. Department of Energy

University of Rochester

Lawrence Berkeley Laboratory 
Jabus B. Roberts

Donald Robson

William S. Rodney

William J. Romo

Louis Rosen

S. Peter Rosen

Hans W. Roser

Serge Rudaz

Alessandro G. Ruggiero

Robert G. Sachs

Mikko E. Sainio

Nicholas P. Samios

Vern Sandberg

Gary H. Sanders

Anders Sandoval

Haiduke Sarafian

Diethard Schiller

Michae1 Schmidt

Lee S. Schroeder

Ryoichi Seki

Brian D. Serot

James R. Shepard

Julian C. Shillcock

Richard R. Silbar

L.M. Simmons

Markus Simonius

Dan Sinclair

Dennis Sivers

Joseph F. Skelly

A.J. Stewart Smith

Gregory R. Smith

Paul A. Souder

David Sparrow

Harold Spinka

Gerard J. Stephenson

Allen Stern

John D. Stevenson

Wolfgang Stoeffl

Yoshiyuki Takahashi

Mitsuyoshi Tanaka

Peter C. Tandy

Robert B. Teese

Lee C. Teng

Kent M. Terwilliger

Henry A. Thiessen

Christoph Tschalaer

Jun-ichi Uegaki

Eric A. Umland
Rice University

Florida State University

National Science Foundation

Carleton University

Los Alamos National Laboratory

Los Alamos National Laboratory

TRIUMF/University of British Columbia

University of Minnesota

Fermilab

University of Chicago

Brookhaven National Laboratory

Brookhaven National Laboratory

Los Alamos National Laboratory

Los Alamos National Laboratory

Lawrence Berkeley Laboratory

Pennsylvania State University

University of Houston

Yale University

Lawrence Berkeley Laboratory

California State University at Northridge

Indiana University

University of Colorado at Boulder

Simon Fraser University

Los Alamos National Laboratory

Los Alamos National Laboratory

ETH Zurich

University of Michigan

Argonne National Laboratory

Brookhaven National Laboratory

Princeton University

University of Karlsruhe

Syracuse University

University of Pennsylvania

Argonne National Laboratory

Los Alamos National Laboratory

University of Texas

University of California at Berkeley

Lawrence Livermore National Laboratory

NASA/Marshal1 Space F1ight Center

Brookhaven National Laboratory

Kent State University

Muskingum College

Fermilab

University of Michigan

Los Alamos National Laboratory

Swiss Institute for Nuclear Research

TRIUMF/University of British Columbia

California Institute of Technology 
Olin van Dyck

W.T.H. van Oers

Onno S. van Roosmalen

Boris Venet

Erich W. Vogt

Thomas Walcher

John Dirk Walecka

Peter J.S. Watson

Jon S. Wesick

Geoffrey B. West

Charles S. Whisnant

D. Hywel White

Harvey B. Willard

Yugi Xue

Ming-Jen Yang

Donald R. Yennie

Gaurang B. Yodh

Glenn R. Young

William C. Zajc

Michael Zeller

Peter D. Zimmerman
Los Alamos National Laboratory

TRIUMF/University of Manitoba

California Institute of Technology

Quincy College

TRIUMF

Max-Planck Institute

Stanford University

Carleton University

TRIUMF/University of Alberta

Los Alamos National Laboratory

University of South Carolina

Brookhaven National Laboratory

National Science Foundation

University of Houston.

University of Chicago

Corne11 University

University of Maryland

Oak Ridge National Laboratory

University of Pennsylvania

Yale University

Louisiana State University 
Appendix 2: Conference Secretaries 
Ms. Chery1 Conrad

Accelerator Dept., B1dg. $911 \mathrm{~B}$

Brookhaven National Laboratory

Upton, NY 11973

(516) 282-4776, FTS 666-4776

Ms. Joanne I. Day .

Argonne National Laboratory

9700 South Cass Avenue

Argonne, IL 60439

(312) 972-6181

Ms. June Goshi

Nuclear Science Division

Lawrence Berkeley Laboratory

Berkeley, CA 97420

(415) 486-7308

Ms. Lorraine Gray

TRIUMF

4004 Wesbrook Ma11

Vancouver, BC V6T 2A3

Canada

(604) 228-4711, ext. 443
Mrs. Marion V. Heimerle

Accelerator Dept., BIdg. 911B

Brookhaven National Laboratory

Upton, NY 11973

(516) 282--4776, FTS 666-4776

Mrs. Roberta Marinuzzi

LAMPF

Los Alamos National Laboratory

Mail Stop 831

Los Alamos, NM 87545

(505) 667--5759, FTS 843-5759

Ms. Karen Poelakker

LAMPF

Los Alamos National Laboratory

Mai1 Stop H846

Los Alamos, NM 87545

(505) 667-6814, FTS 843-6814

Ms. Sue Streicher

Randa11 Laboratory of Physics

The University of Michigan

Ann Arbor, MI 48109-1120

(313) $764--4443$ 